OPEN ACCESS

Edited by:

John Maher,

King's College London,

United Kingdom

Reviewed by:

Toshihiko Imamura,

Kyoto Prefectural University of

Medicine, Japan

Rosana Pelayo,

Mexican Social Security Institute

(IMSS), Mexico

*Correspondence:

Silvia Jiménez-Morales

sjimenez@inmegen.gob.mx

Specialty section:

This article was submitted to

Cancer Immunity

and Immunotherapy,

a section of the journal

Frontiers in Immunology

Received: 06 July 2021

Accepted: 27 October 2021

Published: 18 November 2021

Citation:

Jiménez-Morales S, Aranda-Uribe IS, Pérez-Amado CJ, Ramírez-Bello J and

Hidalgo-Miranda A (2021)

Mechanisms of Immunosuppressive

Tumor Evasion: Focus on Acute

Lymphoblastic Leukemia.

Front. Immunol. 12:737340.

doi: 10.3389/fimmu.2021.737340

\section{Mechanisms of Immunosuppressive Tumor Evasion: Focus on Acute Lymphoblastic Leukemia}

\author{
Silvia Jiménez-Morales ${ }^{1 *}$, Ivan Sammir Aranda-Uribe ${ }^{1,2}$, Carlos Jhovani Pérez-Amado ${ }^{1,3}$, \\ Julian Ramírez-Bello ${ }^{4}$ and Alfredo Hidalgo-Miranda ${ }^{1}$ \\ ${ }^{1}$ Laboratorio de Genómica del Cáncer, Instituto Nacional de Medicina Genómica, Mexico City, Mexico, ${ }^{2}$ Departamento de \\ Farmacología, División de Ciencias de la Salud, Universidad de Quintana Roo, Quintana Roo, Mexico, ${ }^{3}$ Programa de Doctorado en \\ Ciencias Bioquímicas, Universidad Nacional Autónoma de México, Mexico City, Mexico, ${ }^{4}$ Departamento de Endocrinología, Instituto \\ Nacional de Cardiología Ignacio Chávez, Mexico City, Mexico
}

Acute lymphoblastic leukemia (ALL) is a malignancy with high heterogeneity in its biological features and treatments. Although the overall survival (OS) of patients with ALL has recently improved considerably, owing to the application of conventional chemotherapeutic agents, approximately $20 \%$ of the pediatric cases and $40-50 \%$ of the adult patients relapse during and after the treatment period. The potential mechanisms that cause relapse involve clonal evolution, innate and acquired chemoresistance, and the ability of ALL cells to escape the immune-suppressive tumor response. Currently, immunotherapy in combination with conventional treatment is used to enhance the immune response against tumor cells, thereby significantly improving the OS in patients with ALL. Therefore, understanding the mechanisms of immune evasion by leukemia cells could be useful for developing novel therapeutic strategies.

Keywords: acute lymphoblastic leukemia, immunoediting, immunotherapy, tumor immune evasion, immune cells

\section{INTRODUCTION}

Acute lymphoblastic leukemia (ALL) is a group of lymphoid neoplasms derived from B- and Tlymphoid progenitors that are clinically and genetically heterogeneous (1-5). The incidence of ALL is rapidly growing worldwide, and it is estimated to be one in 100,000 persons/year globally $(6,7)$, with a peak prevalence between 1 and 4 years old $(7,8)$ and during the fifth decade of life $(5,9,10)$. The overall survival (OS) for pediatric patients is $>90 \%$ in high-income countries but is lower in middle- and low-income countries (11) - for instance, in Mexico, the global survival rate reported of children with ALL was $63.9 \%$, the event-free survival rate was $52.3 \%$ after an average follow-up of 
3.9 years (12), and it had a high rate of early mortality $(12.1 \%)$ (13). Unfortunately, OS in adults with ALL is worst. Even though most adult patients can reach initial complete remission using recently developed treatments, only $40-50 \%(<20 \%$ in patients aged 60 years or older) of the 5 -year OS is achieved $(5,14-17)$. Relapse, defined as the return of the disease in patients who reach initial complete remission, is one of the main obstacles in achieving improved survival rates (18) and occurs in approximately $20 \%$ of children and $>50 \%$ of adults $(19,20)$. Most relapse incidences appear during treatment (early relapse: $<30$ months after diagnosis) or after treatment completion (late relapse: $<2$ years). Despite the use of diverse anticancer agent combinations (chemotherapy, radiotherapy, and allogeneic hematopoietic stem cell transplantation), patients who experience relapse have a higher probability of treatment failure and death (21). The survival rate of relapsed patients is approximately $50 \%$ and worse in relapsed cases where the central nervous system is affected (22-24). Cancer treatment has been based on the use of chemotherapeutic agents that are unable to differentiate between normal and cancer cells. Emerging therapeutic schemes to treat leukemia are based on the knowledge that the immune system plays an important role in tumor cell identification and elimination (25-28). In order to develop new anti-leukemic therapies, it is necessary to understand the mechanisms underlying the displacement of transformed hematopoietic cells by normal hematopoietic progenitors and the immune evasion processes by which the tumor cells hijack the immune system $(25,26)$. This review focuses on the mechanisms of immune system evasion of ALL cells and its potential for developing new treatments.

\section{IMMUNE SYSTEM AND TUMOR EVASION}

The human immune system comprises leukocytes, bone marrow (BM), and other organs. Leukocytes include neutrophils, monocytes, eosinophils, basophils, dendritic cells, lymphocytes ( $\mathrm{T}$ and B cells), and natural killer (NK) cells. By discriminating self from non-self, the human immune system is responsible for protecting the body from diseases caused by exogenous and endogenous agents. To differentiate between self or non-self, the immune system employs fundamental biochemical differences among cells, such as the absence of methylated cytosine residues in DNA and glycoprotein composition $(29,30)$. The two immune responses recognized are innate and acquired/adaptive (cellmediated immunity and humoral immunity). The innate immune response, which is present from birth, activates a nonspecific immune response in the presence of self-molecules, such as endogenous damage-associated molecular patterns (DAMPs), Toll-like receptor ligands, and non-self-molecules in a cytokine release-dependent manner (31). Acquired immune response involves antibody production by $\mathrm{B}$ cells and antigen presentation to T helper cells to stimulate cytotoxic T cells (CTLs), also known as CD8 + T cells, which induce the elimination of non-self elements and produce immune memory cells (30).

The cell-mediated immunity is activated when a specific CTL is stimulated to initiate the lysis of pathogens, infected cells, and tumor cells; thus, this protects the body against infection and tumor growth, spreading, and metastasis (31). To prevent tumor emergence, the immune system eliminates oncogenic viral infections, induces the inflammatory microenvironment, and destroys malignant cells $(32,33)$. Although tumor cells are self in origin, they differ from their normal counterparts in their biochemical and antigenic characteristics and biological behavior. Cancer cells express tumor-specific neoantigens that arise from an inefficient DNA damage repair system and which are presented to the CTLs by the human leukocyte antigen (HLA) system class I. Then, tumor cells are killed through a combination of direct perforin-dependent destruction and by increasing tumor immune sensitivity through the release of inflammatory cytokines, such as interferon (IFN) alpha (INF$\alpha)$ and tumor necrosis factor (TNF) $(30,34,35)$. However, tumor cells have an acquired mechanism to evade the immune system to avoid their destruction (Figure 1).

In 1908, Ehrlich proposed the role of the immune system in controlling cancer development. Later, Burnet (1957) suggested that lymphocytes are tasked with identifying and eliminating mutated cells $(29,30)$ and the presence of an immunological mechanism for eliminating or inactivating potentially dangerous mutant cells before tumor clinical manifestations, a concept called "immunological surveillance" (36). Currently, the role of the immune system in malignant cell elimination is unequivocally established. The quality control of the immune system to fight against tumor cells involves immune cells and their associated molecules, with the CTLs and NK cells being the major components $(34,37)$. These cells act as tumor suppressors by patrolling the human body and destroying transformed cells before tumor progression. The anti-tumor immune response attacks the tumor through activated lymphocytes to trigger apoptosis by producing perforin and granzyme B to damage the extracellular membrane and enter targeted tumor cells, expressing Fas-L, TNF-related apoptosis-inducing ligand, and IFN-gamma (IFN- $\gamma$ ) (38-40). However, tumor cells can evade immune surveillance mechanisms, and indirectly, the immune system selects tumor cells that carry mutations in genes involved in the immune detection and elimination pathways, leading to cancer progression (Figure 1). Despite that CTLs detect tumor cells, they frequently fail to control tumor growth $(41,42)$. CTL dysfunction could be induced by a continuous stimulation of the tumor antigens and by an immunosuppressive tumor microenvironment (TME), driving the $\mathrm{T}$ cells to a functionally exhausted state and cancer progression $(42,43)$. The interaction between the immune system and cancer establishment is called immunoediting.

The central assumption of immunoediting is that CTLs recognize tumor antigens and drive immunological tumor elimination or model cancer development before re-emerging. This process could select cancer cells with mutations that confer resistance to immune effectors and survival advantages in a tumorigenic environment $(44,45)$. Immunoediting comprises three phases: elimination, equilibrium, and evasion (30). These mechanisms have been extensively reviewed elsewhere; thus, they are briefly summarized here. 


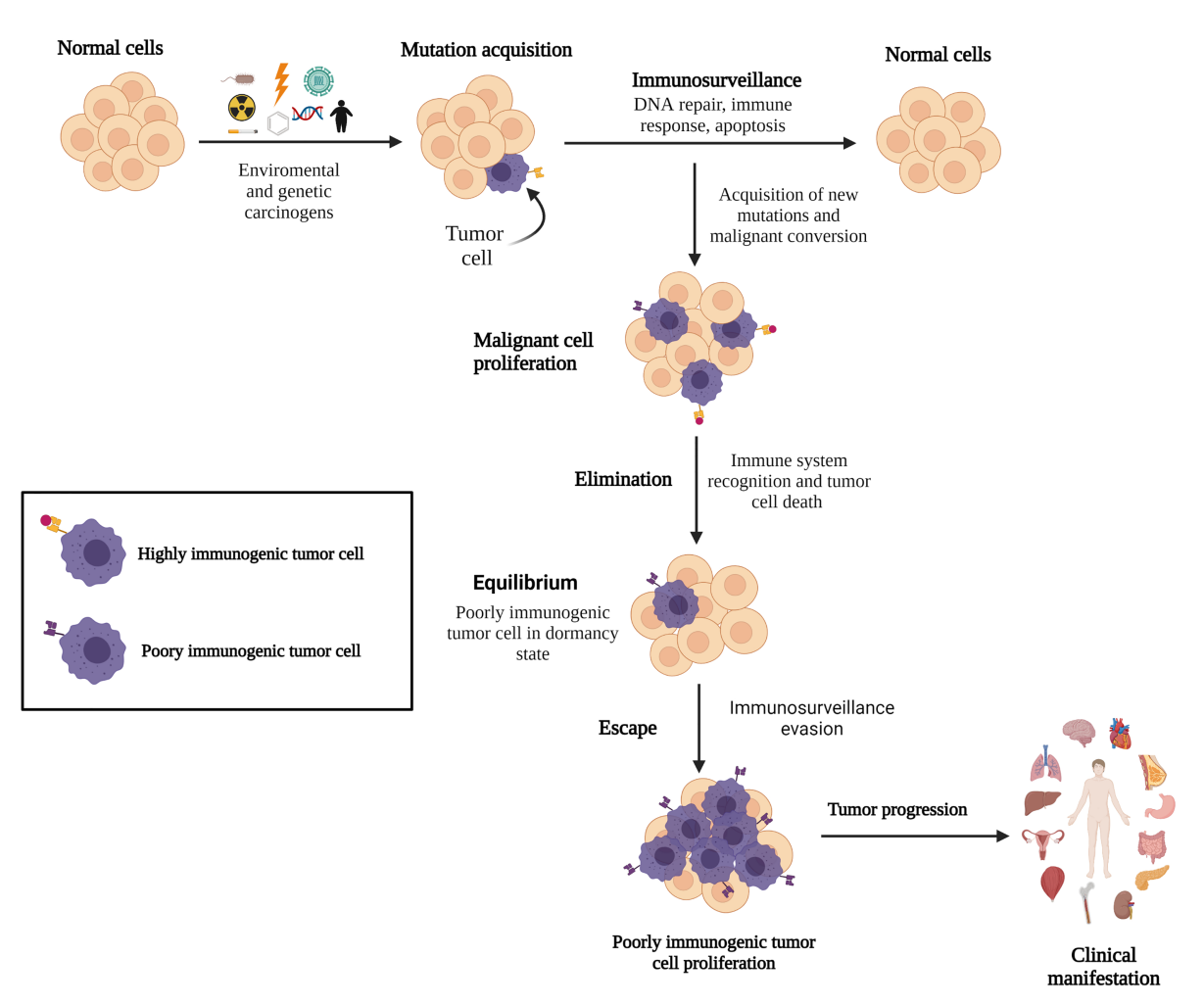

FIGURE 1 | Immune surveillance and cancer development. Emerging malignant cells are identified and eliminated by the immune system; however, certain acquired gene mutations in tumor cells allow them to remain undetected by the immune surveillance system, resulting in cancer.

Elimination phase involves the recognition and killing of transformed cells and nascent tumors by the immune system through antibody production. This process starts with the recruitment of macrophages, dendritic cells, and infiltrating lymphocytes (NK and natural killer $\mathrm{T}$ cells) into the tumor site (46) to suppress angiogenesis and induce immunogenic necrotic tumor cell death, promote regulatory $\mathrm{T}$ cells (Tregs) apoptosis, and induce M1 pro-inflammatory macrophage activity to defeat tumor progression (47). Moreover, INF- $\gamma$ and interleukin-12 (IL12) enhance cytotoxic responses by NK and CTL cells, promoting tumor death by apoptosis and the release of reactive oxygen and nitrogen intermediates (47). Tumorspecific $\mathrm{CD} 8+$ and $\mathrm{CD} 4+\mathrm{T}$ cells infiltrate the tumor site after the recognition of tumor-specific or tumor-associated antigens through HLA class I and class II molecules, respectively, which facilitate the immune mechanisms in synergy with B cells. Cancer cells that are not eradicated during the elimination phase remain in dormancy or equilibrium (Figure 1) $(33,43)$.

Equilibrium is the longest phase where cancer remains clinically undetectable, suggesting that tumor cells coexist with the immune system for up to several years $(47,48)$. Evidences have shown that immune-mediated cancer dormancy is regulated by CD8+ and CD4+ T cells and IFN- $\gamma(49,50)$. Through IFN- $\gamma /$ STAT1 pathway activation, IFN- $\gamma$ inhibits tumor cell proliferation and establishes tumor dormancy without destroying malignant cells (30). However, IFN- $\gamma$ can facilitate tumor escape and relapse by inducing tumor antigen loss, upregulating programmed death 1 (PD1) ligand (PD-L1) in tumor cells and recruiting myeloid-derived suppressor cells (MDSCs) and tumor-associated macrophages (TAMs) to the tumor site (50).

Escape is the phase where tumor cells that have evaded the immune surveillance system acquired additional DNA mutations and epigenetic changes and have great effectiveness to proliferate and evade apoptotic mechanisms (51). Although new mutations could drive the expression of tumor-specific antigens that are recognized by CTL cells (52), tumor cell-intrinsic alterations and TME modifications (e.g., nutrient depletion, metabolic stress, and cytokine regulation) lead to poor immune response and tumor progression (53). Long-term glucose deficiency in the TME results in low $\mathrm{T}$ cell response, cytokine production impairment, $\mathrm{T}$ cell "anergy" state, and T cell autophagy to save energy $(54,55)$. Lipid reduction may result in a lower tryptophan concentration in the extracellular environment, which can inhibit CTL proliferation (47, 56). Acquisition of gain-of-function mutations by tumor cells could lead to low or lack of antigenicity properties, resulting in hijacking of immune mechanisms. Mutations can also induce abnormal HLA expression or antigen processing machinery dysregulation; in fact, HLA class I downregulation is described in $40-90 \%$ of human tumors $(45,51)$. Altered PD-1 or PD-L1 expression on tumor and host cells is also observed, which can inhibit $\mathrm{T}$ cell activation and enhance the immune tolerance of malignant cells, facilitating tumor 
immune escape $(57,58)$. Chronic PD-L1 expression, predominantly by TAMs, prolongs the immunosuppressive TME, likely by tumor-specific T cells, as if they were malignant cells (57). Studies in ALL have shown that leukemic blasts express ligands for NK cell receptors, the natural killer group 2 member D (NKG2D) and DNAX accessory molecule-1, to avoid their destruction (59). Low numbers and impaired NK-cell-mediated cytotoxicity could be due to a reduced level of activating receptors (NKp46, NKp30, NKp44, and NKG2D). Cancer cells can also alter NK cell function by modulating the NK cell surface receptors, releasing soluble factors with immunosuppressive properties such as IL-10 and transforming growth factor beta (TGF- $\beta$ ). The signaling lymphocytic activation molecule-associated protein adaptor, in addition to the overexpression of human leukocyte antigen $G$ (HLA-G), which induced immune tolerance and decreased NKG2D expression in NK cells, contributes to the escape of leukemia cells from immune surveillance $(60,61)$. Thus, the immune system indirectly promotes tumor progression through the selection of poorly immunogenic malignant clones $(44,45)$. Table 1 lists the general mechanisms involved in the evasion phase.

\section{IMMUNE EVASION MECHANISMS IN ALL}

Several studies have shown that solid and liquid tumors share immune evasion mechanisms. Studies on B cell precursor (pre-B) ALL mouse models to analyze the cytotoxicity effect of CTLs on nonimmunogenic leukemic cells revealed that leukemic blasts, which are not eliminated by the initial immune response, remain in a dormant state during immune surveillance until an immune-evasive clone emerges, which requires a loss of immunogenic antigens for immune escape (77). In addition, it was proposed that ALL displayed immunological ignorance or immune tolerance (described as poor immunogenic clones that fail to alert the immune sensing mechanisms and avoid immune response) because leukemia cells lack or only a subset of them express relevant co-stimulatory accessory molecules (CD80 and CD87, respectively), showing deficient $\mathrm{T}$ cell activation $(78,79)$. Moreover, the relatively low mutation burden in ALL in comparison to other tumors could reduce neoantigen production and induce a low immunogenic response (80-82). Nevertheless, the presence of tumor-infiltrating lymphocytes as CD8+ T cells in pediatric patients with ALL suggests a potentially robust antitumor immune response (83). In addition, by predicting mutated neoepitopes in leukemia, at least one neoepitope was found in $88 \%$ of the cases, which can be recognized by CTLs and induce an anti-tumor response (84). However, B cell leukemia fails to function as an antigen-presenting cell (APC) which, in addition to its rapid dissemination, could affect the initiation and execution of antileukemia immunity through non-activation of $\mathrm{T}$ cells, which may promote immunosuppressive TME and tumor cell survival $(55,85-$ 87). In ALL, it has been proposed that tumor-specific $T$ cells are never properly activated; they are instead deleted or anergized upon initial antigen presentation $(80,85)$. Data from pre-B cells ALL show that the $\mathrm{T}$ cells become anergic after interleukin-10 (IL-10) expression, which is induced by CD40 activation $(80,85)$. Abnormal IL-10 and CD40 expression has been found in patients with ALL $(78,79,88-$ 90 ), and polymorphisms within the $I L-10$ gene promoter region $(-\mathrm{G} 1082 \mathrm{~A})$ that influences the IL-10 plasma levels have been associated with ALL prognosis $(78,91,92)$.

Immune tolerance mechanisms that protect healthy tissues are hijacked by cancer to maintain immune escape through the modulation of additional processes, such as metabolically essential amino acid (tryptophan and arginine) depletion, immunosuppressive cytokine (TGF- $\beta$ and IL-10) overproduction, expansion of Tregs, MDSCs, macrophages, and expression of T cell response inhibitors and co-inhibitory ligands (e.g., PD-L1) (93). Studies focused on ALL suggest that defective antigen presentation on MHC-I molecules is involved in immune evasion (94). Alterations in the expression and functionality of HLA class I (essential for CTL cytotoxicity) or II (important for CD4+ T cell response) are commonly observed in solid tumors $(95,96)$. The downregulation or loss of cell surface expression of HLA-I and high

TABLE 1 | Potential mechanisms of tumor immune evasion.

\begin{tabular}{|c|c|c|c|}
\hline Mechanism & Features & Tumor types & References \\
\hline Malignant cell selection & $\begin{array}{l}\text { Low effectiveness to eliminate mutated cells } \\
\text { Gain of DNA and epigenetic mutations that } \\
\text { increase the proliferation ability } \\
\text { Resistance to immunity-induced apoptosis (by } \\
\text { abnormal function of IFN } \gamma \text { receptor or tyrosine } \\
\text { kinases association) }\end{array}$ & $\begin{array}{l}\text { ALL, breast, bladder, colorectal, CML, esophageal, endometrial, HN, } \\
\text { hepatocellular, gastric, glioblastoma, lung, lymphoma, melanoma, } \\
\text { pancreatic, prostate, ovarian }\end{array}$ & $(62-67)$ \\
\hline $\begin{array}{l}\text { Altered expression of HLA } \\
\text { antigens and co-stimulatory } \\
\text { molecules }\end{array}$ & $\begin{array}{l}\text { Reduced of HLA-I antigen expression } \\
\text { Abnormal expression of co-stimulatory molecules } \\
\text { (CD80 or CD86) } \\
\text { Poor stimulation of T cells } \\
\text { Reduced CTL response }\end{array}$ & $\begin{array}{l}\text { ALL, CLL, AML, CML, breast, cervical, colorectal, gastric, } \\
\text { hepatocellular, lymphoma, lung, melanoma }\end{array}$ & $\begin{array}{c}(55,60,68, \\
69)\end{array}$ \\
\hline $\begin{array}{l}\text { Chronic PD-L1 expression } \\
\text { by host cells }\end{array}$ & $\begin{array}{l}\text { Prolongated immunosuppressive state in the } \\
\text { tumor microenvironment } \\
\text { Repressed T-cell function }\end{array}$ & $\begin{array}{l}\text { ALL, CML, breast, colorectal, esophageal, gastric, HN, lung, } \\
\text { melanoma, ovarian, sarcoma }\end{array}$ & $\begin{array}{l}(55,57,58 \\
70,71)\end{array}$ \\
\hline T cell dysfunction & $\begin{array}{l}\text { Reduced T-cell response } \\
\text { Cytokine production impairment } \\
\text { T-cell "anergy" and autophagy }\end{array}$ & $\begin{array}{l}\text { ALL, CLL, breast, glioblastoma, lung, hepatocellular, melanoma, } \\
\text { ovarian, sarcoma }\end{array}$ & $\begin{array}{l}(55,62 \\
72-76)\end{array}$ \\
\hline
\end{tabular}

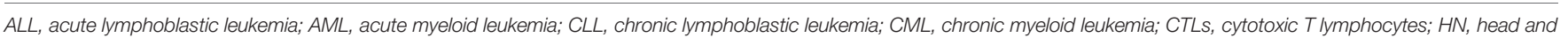
neck; TAM, tumor-associated macrophages; APCs, antigen-presenting cells. 
resistance to NK-cell-mediated killing has been described in ALL (97-101) - for instance, the C2 epitope that is encoded by HLA-C has been found to be overrepresented in patients with ALL. Given that C2 is a high-affinity ligand of the natural killer cell inhibition receptor (KIR2DL1), it has been suggested that C2 may decrease the destruction of leukemic blasts and increase the probability of late relapse in patients with ALL ( $>2.5$ years) by reducing the cytotoxic capacity of NK cells (99). The absence of HLA class II expression in leukemic T-cells and its regulator class II trans activator has been reported (102). Recently, HLA class II expression was associated with a better prognosis in adult T cell leukemia/lymphoma (103).

Other mechanisms, such as disrupted immune checkpoint expression and high production of suppressor factors by CTLs, alterations in the anti-inflammatory/pro-inflammatory cytokine ratio, cytotoxic abnormalities, and other cell populations with altered functions, and aberrations in the immunophenotype of the lymphoid lineage have been proposed to avoid immune surveillance by ALL cells (Figure 2) $(85,104)$.

\section{Disrupted Immune Checkpoint Expression and High Production of Tumor Suppressor Factors by Cytotoxic T Cells}

Cytotoxic cells are the major components of the immune system that counterattack tumor cells. The overexpression of co-inhibitory ligands for specific receptors on cancer cell surfaces to disrupt $\mathrm{T}$ cell response is one of the primary mechanisms developed to hijack the immune system. The cell surface molecules CD28, cytotoxic Tlymphocyte-associated protein 4 (CTLA-4), inducible costimulator (ICOS), PD1, and PD-1L are basic ligands that induce co-stimulatory or inhibitory signals in T cells to maintain immune system homeostasis (Figure 2A) (105). In the early immune response stages, $\mathrm{CD} 28$ facilitates and maintains the $\mathrm{CD} 4+$ and CD8+ T cell response. CTLA- 4 arrests T cell activation by triggering an inhibitory signal within the $\mathrm{T}$ cell, affecting critical peripheral $\mathrm{T}$ cell tolerance and function (106). CD28 and CTLA-4 share ligands and are necessary to avoid inappropriate or prolonged CD4+ and CD8+ $\mathrm{T}$ cell activation. Both molecules have been found to be constitutively expressed in acute myeloid leukemia (AML) blasts at diagnosis and have an increased expression in leukocytes from the peripheral blood of these patients compared with that of healthy controls, likely favoring AML cell escape from $\mathrm{T}$ cell activation and its effector functions (107). An evaluation of the CTLA-4 expression revealed that this co-inhibitory molecule was elevated in $\mathrm{T}$ cells in patients with high-risk ALL (108); in addition, CTLA-4 solubility was significantly elevated in $70 \%$ of B-ALL pediatric patients with active disease (109). Furthermore, CTLA-4 overexpression has been correlated with the percentage of leukemic B cells and poor prognosis in pediatric patients $(108,110)$, and a high serum CTLA-4 level has been detected in patients with B-ALL who died from the disease (111). Thus, the disputed CTLA-4 expression from ALL cells could be a potential mechanism of immune surveillance escape $(109,112)$.

PD-1 and PD-L1 overexpression has been reported to evade the host immune system in numerous cancer types $(105,110,113)$. PDL1 and PD-L2 are ligands of PD-1, which is an important inhibitory immune checkpoint that suppresses $\mathrm{T}$ cell activity after antigen activation. In fact, CTL function inhibition by PD-1 expression has been observed in patients with AML (113). CTLA-4 and PD-1 expression in hematological malignant cells has been suggested as an immune evasion strategy to promote leukemia blast survival and prevent efficient recognition and destruction by anti-tumor $\mathrm{T}$ cells $(107,110)$. Studies using a mouse model of disseminated AML and in transplanted patients before relapse have shown that sustained inhibitory signaling mediated by CTLA- 4 and PD- 1 on T cells correlates with a $\mathrm{T}$ cell exhaustion stage, reduced $\mathrm{T}$ cell effector function, and lower cytotoxicity $(114,115)$. Data from ALL evidenced a decrease in PD-1 expression on CD4+ and CD8+ T cells after the inhibition of myeloid-epithelial-reproductive tyrosine kinase, a gene associated with the induction of an antiapoptotic gene expression signature in B-ALL cells, leading to increased $\mathrm{T}$ cell activation (116). Abnormal expression of checkpoint molecule PD1 has been reported in BM biopsies from adult patients and in $\mathrm{T}$ cells of pediatric cases with ALL $(108,117)$. In addition to the observations in ALL, upregulation of both malignant and infiltrating immune cells from B cell lymphomas and T cells of peripheral blood mononuclear cells from patients with chronic myeloid leukemia (CML) exhibits the relevance of PD-L1 in hematological malignancies (118-120). PD-L1 overexpression is correlated with poor prognosis in ALL (113) and has been found to be one of the most expressed inhibitory markers in pediatric ALL blast, whose expression is increased in relapsed patients with ALL $(108,115)$. Other checkpoint molecules are T cell immunoglobulin and mucin domain-containing protein 3 (TIM-3) and lymphocyteactivation gene 3 (LAG-3). TIM-3 is involved in apoptosis, and Tregs expressing TIMP3 have a higher suppressor function than Tregs negative to TIMP3 (121). LAG-3 expression has been detected in highly immunosuppressive $\mathrm{T}$ cells and correlates with an increased expression of IL-10 production by Tregs $(122,123)$. TIM-3 and LAG-3 have been found to be subexpressed in the BM of patients with ALL, in contrast to healthy subjects (117).

ICOS (CD275) is involved in maintaining immune reactions and has a relevant role in Tregs function and differentiation, which protects tumor cells from immune cells in the TME (124, 125). Significant Tregs accumulation in the BM-TME and upregulation of ICOS ligand (ICOS-L) have been observed in AML, suggesting that ICOS-L contributes to the conversion and expansion of Tregs and preserves the immunosuppressive environment. Additionally, ICOS-L and ICOS expression was found to be a predictor of OS and disease-free survival in patients with AML (126). Although there is no information regarding ICOS or ICOS-L in ALL, the relevance of ICOS in ALL immune escape is supported by studies showing that ICOS is part of the intracellular region of the signaling domain complexes that activate and induce cytotoxicity against target cells during chimeric antigen receptor (CAR) T cell immunotherapy (127).

\section{Alterations in the Anti-inflammatory/Pro- Inflammatory Cytokine Ratio}

Inflammation is an immune response to body damage and is mediated by cytokines, which are relevant players involved in oncogenic processes, such as cell proliferation, apoptosis inhibition of mutated cells, and promotion and progression of cancer development (128). Cytokines are classified as proinflammatory (IL-1 $\beta$, IL-6, IL-15, IL-17, IL-23, IFN- $\alpha$, and 
TNF- $\alpha$ ) and anti-inflammatory (IL-4, IL-10, IL-13, and TGF- $\beta$ ). Interestingly, an inflammatory marker analysis of neonatal blood reported that children who developed pre-B ALL had a cytokine signature (lower concentrations of the cytokine IL-8, soluble IL-6 receptor $\alpha$, and TGF- $\beta 1$ and higher concentrations of IL- 6 , IL17 , and IL-18) (129). Increased CCL2 and IL-8 concentrations of $\mathrm{T}$ cell-polarizing cytokines (IFN- $\gamma$ and IL-12) and cytokines associated with infectious processes, such as TNF- $\alpha$ and IL-6, have been detected in patients with ALL at diagnosis, suggesting a pro-inflammatory state (130-133). These findings could be associated with immune cell activation by endogenous molecules that are released after tissue injury or cell death to generate an immune response against cancer $(133,134)$. The proinflammatory environment in the $\mathrm{BM}$ of patients with leukemia is facilitated by hematopoietic and stromal cells. However, studies indicate that cancer cells hamper immune activation by creating an anti-inflammatory TME by overproducing anti-inflammatory cytokines and by blocking the release of pro-inflammatory cytokines, thus successfully evading immune surveillance $(128,135)$. In CML, AML, and ALL, cancer cells express TGF- $\beta$ and IL-10 to reduce immunogenicity $(136,137)$. Studies in mouse models with BALL have shown that TNF- $\alpha$ is secreted by B-ALL cells, and this leads to increased invasiveness and significant prolongation of surviving leukemia cells (138), which is an important mediator of leukemia-induced NK cell dysfunction. Thus, it is fundamental for NK cell immune evasion in childhood B cell ALL (139). Although IL-4 has shown antitumor effects and ALL cell suppression (140), it has been suggested that IL-4 expression in leukemia cells could reduce immunological recognition by decreasing HLA-class II molecule expression (132).

IFN- $\gamma$ and interleukin 6 (IL-6) are among the most important cytokines associated with immune response in cancer (141). IFN- $\gamma$ gene expression is reduced in patients with ALL, suggesting that the immune system is disrupted and leukemia cells may take advantage of defective IFN- $\gamma$ production to promote escape from immune surveillance $(142,143)$. IL-6 contributes to lymphocyte and monocyte differentiation and induces antibody secretion by $\mathrm{B}$ cells. The low antibody production and decreased cellular immunity derived from abnormal IL-6 expression detected in ALL cases (Figure 2B), in addition to the association between single-nucleotide polymorphisms in the $I L$ - 6 gene and susceptibility
A Disrupted expression of immune checkpoints

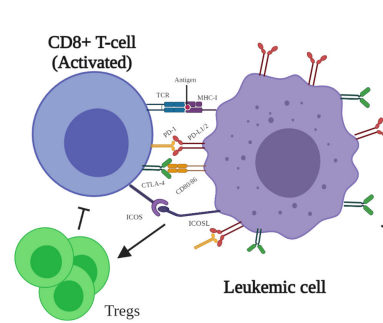

C Abnormal immune cell populations
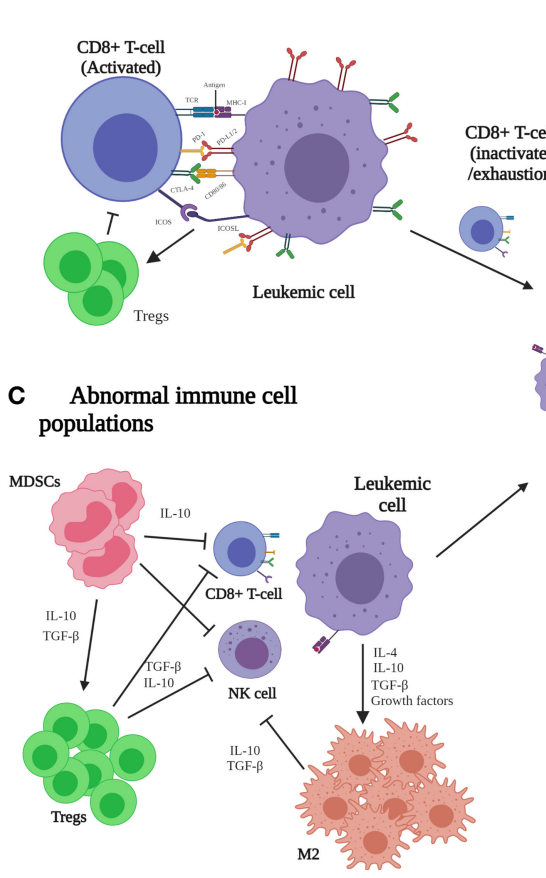

B Alterarion of anti-inflammatory/ pro-inflammatory cytokines ratios

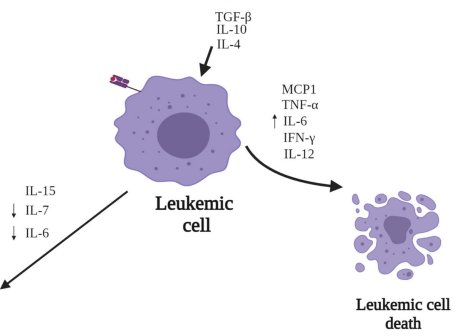

D Leukemia cell plasticity and immunphenotype switching proliferation

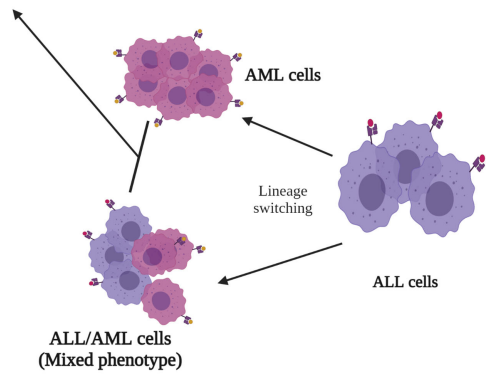

FIGURE 2 | Immune evasion mechanisms that are potentially involved in the progression of acute lymphoid leukemia (ALL). (A) Low MHC-I and co-stimulatory ligands but high co-inhibitory lead to the inactivation or depletion of the CD8+ T-cell cytotoxic function. (B) Abnormal expression of anti-inflammatory cytokines (TGF$\beta, I L-4$, and IL-10) reduces the cytotoxic T Iymphocyte (CTL) population, and the pro-inflammatory cytokines (MCP1, TNF- $\alpha$, IL-6, IL-12, and IFN- $\gamma$ ) are responsible for malignant cell destruction. (C) Immune cell enrichment, such as MDSCs, Tregs, and M2 macrophages, generates a favorable microenvironment for ALL cells and inhibits the activation and differentiation of CTLs and natural killer cells. (D) The plasticity of ALL cells leads to immunophenotype switching, which can reprogram immune evasion pathways. It has been proposed that these mechanisms could together contribute to the dissemination and progression of ALL. ALL, acute lymphoblastic leukemia; AML, acute myeloid leukemia; CD, cluster differentiation; CTLs, cytotoxic T lymphocytes; CTLA-4, cytotoxic T-lymphocyte-associated protein 4; ICOS, inducible co-stimulator; ICOS-L, inducible co-stimulator ligand; IFN- $\gamma$, interferon gamma; IL, interleukin; M2, M2 macrophages; MCP1, chemoattractant protein-1; MDSC, myeloid-derived suppressor cells; MHC-I, major histocompatibility complex class I; NK, natural killer; PD1, programmed death 1 ligand; PD-L1/2, programmed death 1/2 ligand; TCR, T-cell receptor; TNF- $\alpha$, necrosis factor alpha; Treg, regulatory T-cell. 
to ALL (the genotype of which correlated with IL-6 serum levels), are evidence of the relevance of this cytokine in this malignant disease $(141,144,145)$.

Other cytokines and chemokines, such as IL-1, IL-7, IL-8, CCL2, CXC-10, and CXCL-12, could contribute to immunotolerance (112, 146). In fact, IL-1, IL-7, and CXCL12 expression favors ALL cell surveillance in the BM-TME $(146,147)$. Through the induction of CCL2 by periostin, this molecule stimulates the proliferation and dissemination of ALL $(146,148)$.

\section{Abnormal Cytotoxic and Other Cell Populations and Alteration of Their Functions}

The abnormal proliferation of immune cell populations is another important mechanism for preventing immune attacks in cancer. Two distinct $\mathrm{T}$ cell subsets are involved in the immune system against cancer. The first is CTLs that kill cancer cells, and the second is cells required for the activation and proliferation of APCs.

Tregs (CD4+CD25+ Foxp3+) are involved in tumor development and progression by inhibiting anti-tumor immunity in the $\operatorname{TME}(93,149)$. Under physiological conditions, Tregs play an essential role in self-tolerance and immune homeostasis processes by suppressing normal and pathological immune responses and by eliminating a broad range of pathogenic microorganisms and malignant cells $(85,150-152)$. The correlation between tumorinfiltrating Treg levels and prognosis has been described in several malignancies, including ALL, suggesting that Tregs may be involved in the immune evasion process $(149,153-156)$. Indeed a high number of Tregs in the BM and peripheral blood of ALL cases has been associated with poor prognosis $(153,154,157,158)$. Studies in BM-TME have shown that immunosuppressive cytokines, such as IL-10 and TGF- $\beta$, are secreted by Tregs (Figure 2C) (159).

One of the biological features of patients with ALL is the presence of severe cytopenia and poor reconstitution of the innate and adaptive immune system. Although normal lymphoid and myeloid cells are present in ALL BM, the early compartment of progenitor hematopoietic cells is reduced in number and activity, including NK cells, MDSCs, and macrophages $(93,130,160)$.

NK cells represent 5-20\% of the lymphocytes in peripheral blood and are relevant in early antitumor immune response by lysing the tumor cells due to cytokine release. Based on CD56 and CD16 expression, two principal subpopulations of NK cells were identified: cytotoxic NK cells or cNK (CD56dim CD16+) and regulatory NK cells or NKregs (CD56highCd16-). cNK are abundant in peripheral blood ( $95 \%$ of the NK) and inflammation sites and show a higher cytotoxic capacity than NKregs, which predominate in lymphoid nodes (33). Natural cytotoxic receptor expression is a relevant mechanism to stimulate responses against tumor cells and has been observed to be downregulated in ALL BM (33). In recent years, several studies have provided evidence of the fundamental role of NK cells in the onset, development, and establishment of ALL (59, 139, 161, 162). ALL NK cells at diagnosis had an inhibitory phenotype associated with impaired function due to abnormal NK ligand expression (139). Torrelli et al. (59) observed a higher expression of the ligands for NK cell-activating receptors, Nec2, ULBP1, and UBLP3, on the surface of the blasts from children in contrast to adults with ALL, which could be associated with the worse clinical evolution of ALL in adults than in children (59). Differences in NK cell activity among molecular ALL subtypes have been described, with increased NK cell-activating ligand expression (NKG2D and DNAM1) in patients with ALL carrying the fusion gene $B C R-A B L$ (Philadelphia chromosome: $\mathrm{Ph}+$ ), in contrast to $\mathrm{Ph}$ negatives (59). Additionally, $\mathrm{Ph}+$ cells are more susceptible to NK cell killing activity than ALL cells carrying no known molecular markers and were enhanced in $\mathrm{Ph}+$ adult cases; B-ALL with MLL-AF4 gene and T-ALL cases displayed a high density of the NKG2D ligand and UL16-binding protein (ULBP-1) (59). NK cells from child and adult patients have shown aberrant functions, such as low degranulation of granzyme B $(117,139)$. In a cohort of child patients with B cell ALL sampled at diagnosis, end induction, and maintenance, evidence of altered NK phenotype and function compared to age-matched controls was revealed. It should be emphasized that the NK abnormalities were partially corrected during the maintenance phase of the ALL treatment and were inducible in healthy NK cells after co-culture with ALL blasts in vitro by TGF$\beta 1$ release (139). In fact, leukemic cells secrete IL-10 and TGF- $\beta$ in order to evade the effect of CTLs and NK cells (137). Furthermore, a direct contribution of the TME to the exhaustion of NK cell functions by the CRTAM/Necl-2 interaction was reported in ALL. Indeed the decreased NK cell content and their depleted cytotoxic capacity in peripheral blood are two of the predominant immune surveillance problems in acute leukemia (139). Current investigations focusing on in vitro activation and NK cell expansion protocols to treat ALL are underway.

MDSCs are a heterogeneous population of regulatory immature cells derived from monocytes or granulocytes that are involved in immunosuppression in patients with cancer (163). MDSCs consist of two main subpopulations (monocytic MDSCs-MO-MDSCs and polymorphonuclear MDSCsPMN-MDSCs) that suppress the activation, proliferation, and cytotoxicity of effector $\mathrm{T}$ and $\mathrm{NK}$ cells and induce the differentiation and expansion of Tregs (163-165). The role of MDSCs in ALL remains incomplete. Recently, it was reported that patients with B cell ALL at diagnosis have a higher number of MDSCs than healthy subjects, which was even higher during induction chemotherapy (166). Furthermore, Zahran et al. (163) detected increased MDSCs in pediatric patients with B cell ALL compared to healthy controls. Moreover, these authors observed a relationship between PMN-MDSCs and the levels of peripheral and $\mathrm{BM}$ blast cells and $\mathrm{CD} 34+$ cells, suggesting that PMNMDSC cells provide a suitable immune-suppressive state for $\mathrm{B}$ cell ALL tumor progression. A reduction in PMN-MDSC population was related to complete post-induction remission (163). The high number of these cells in pediatric patients with $B$ cell ALL suggests that the increased levels and activity of MDSCs and Tregs could explain the immunosuppression state observed in this malignancy (163). MDSCs secrete TGF- $\beta$ and IL-10 that have direct immunosuppressive effects and induce Treg 
expansion, which suppressed tumor-specific $\mathrm{T}$ cell responses (167) (Figure 2C).

Macrophages are other essential immune cell populations of the host and are composed of two subtypes: M1, which has antitumor effects, and M2 (anti-inflammatory cells with protumoral properties), which supports TME through the induction of angiogenesis, metastasis, and immune suppression (168-170). Macrophages have anti-tumoral activities at the initial stages of solid and hematological tumor development; however, TME impairs macrophage function, transforming them into immunosuppressive cell types with pro-tumoral activities (171). The frequency of M1 macrophages has been reported to be notably reduced in adult patients with B-ALL compared to controls, while M2 macrophages are increased (117). M2 is divided into several subtypes, where TAMs, which are relevant in solid tumor cell invasion, are included. Knowledge about the role of macrophages in hematopoietic malignancies has been obtained mainly from the study of lymphomas, where an association between the number of TAMs in lymph node biopsy and the prognosis of patients with classical Hodgkin lymphoma (cHL) was found (172). In ALL, the production of M2 macrophages with immunosuppressive/tolerogenic properties can be induced by tumor-mediated mechanisms (tumorderived cytokines and growth factors, etc.) (171). Furthermore, it has been found that spleen leukemia-associated macrophages (LAMs) stimulate the proliferation of T cell ALL and have high migration, and their functional and phenotypic characteristics are modified by an organ-specific microenvironment $(169,173)$. Most LAMs have an M2-like phenotype. It has been reported that this type of immune cells also secrete immunosuppressive cytokines such as IL-10 and TGF- $\beta$ (159).

\section{Leukemia Cell Plasticity and Immunophenotype Switching}

During malignant hematopoietic disorders, such as acute leukemias, intrinsic and extrinsic signals (including those participating in immune surveillance) influence the cell differentiation pathway and cooperate in abnormal fate decisions, highlighting the relevance of a continuous homeostatic control to produce elements of tumor suppression $(174,175)$. Switching of CML to ALL in the blast crisis, AML cases relapsing as ALL, ALL converting AML after chemotherapy, and mixed phenotypes (simultaneous expression of both myeloid and lymphoid antigens) suggest that linage-associated molecule expression contributes to immune response disruption and facilitates cancer progression (174, 176179). Lineage switching in leukemia is more frequent in children than in adults, and most cases are ALL converting to AML (180). Studies have proposed that this process is a consequence of stem cell plasticity (capacity to cell fate conversion in defined cells adopting biological properties to the same or different lineages) since the evidence shows that cancer cells are derived from the same founder clone in leukemia lineage switching (180). Leukemias with lineage switching appear to be more common in specific genetic subtypes, such as those with KMT2A (MLL) gene rearrangements (180). The absence of EBF1 expression in ALL allows early lymphoid progenitors to differentiate into the myeloid lineage, and deletion of PAX5 in mature B cells can induce conversion to different fates, including macrophages and $\mathrm{T}$ cells $(176,181)$. Low PAX5 expression has been reported in patients with ALL and very early relapse-expressing AML genes, such as MPO and FLT3 (174). A single-cell RNA-seq study revealed that plasticity coexists with oncogenic and immune evasion programs in early $\mathrm{T}$ progenitor ALL (174), suggesting that specific features acquired during lineage conversion could contribute to immune evasion response in ALL. It has been proposed that the plasticity of leukemic blasts in early progenitor T cell ALL can modulate the treatment based on inhibitors of the Notch pathway due to the coexistence of transcriptional programs that are characteristic of lymphoid and myeloid lineages. Additionally, immunoevasion signatures were found to be activated in the TME-for example, the interaction between hepatitis A cellular virus receptor 2 and galectin 9 is associated with CD8+ T cell dysfunction (174). Studies aimed at understanding leukemic blast plasticity could contribute to the identification of potential therapeutic targets based on the reversion of $\mathrm{T}$ cell depletion and consequently improve OS rates in patients with ALL.

\section{BONE MARROW TUMOR MICROENVIRONMENT AND IMMUNE SYSTEM EVASION}

Immunological evasion is due to mechanisms inherent to the TME. It is well known that malignant blasts maintain a close interaction with normal cells within the BM niche and, at the expense of normal hematopoiesis, remodel functionally and structurally the BM-TME to favor ALL development and promote tumor cell dissemination and chemotherapy resistance $(43,47,55,112,118,182-184)$. BM-TME favors tumor growth through polarization of host immunity to prevent anti-cancer immune responses. Alterations in immune cell populations in the TME are other mechanisms involved in the immune evasion by leukemic cells-for instance, it has been reported that the presence of leukemic cells in BM affects the CD14-expressing monocytes and non-classical CD16-expressing monocytes populations (185). Leukemic blasts have the capacity for TME remodeling during disease progression and promote monocyte differentiation into non-classical monocytes. In the BM-TME, a decrease in CTLs and NK cells has also been reported as well as an increase in suppressor immune cell populations such as Tregs, M2 macrophages, and MDSCs to support an immunosuppressive microenvironment (55). Mice models of AML revealed that those leukemic cells reduce the osteoblast population, modifying the lineage fate of hematopoietic stem cells, which increase tumor burden and reduce OS $(186,187)$. The interaction between leukemic blasts and the different cell types has been associated with a major surveillance of tumor cells (188). Besides this, ALL cells and the primary mesenchymal stromal cells (MSC) within the niche interact by using tunneling nanotubes (TN) that induce the secretion of prosurvival cytokines IL-8, CCL2, and CXCL10, driving stroma-mediated steroid resistance. By interruption of the TN signal, the leukemogenic processes are inhibited; thus, 
pre-B-leukemic cells are resensitized with prednisolone (189, 190).

ALL blasts also express surface molecules shared with hematopoietic stem cells and interact with extracellular matrix (ECM) molecules, soluble factors, and cytokines for ALL promotion-for instance, it has been reported that integrins have a role in the retention of leukemic blasts in the BM and contribute to ALL dissemination from BM to the CNS and chemoresistance $(191,192)$. Otherwise, the MSC-derived ECM proteins, such as periostin and osteopontin in the niche, stimulate the proliferation and dissemination of ALL. ECM of the $\mathrm{BM}$ also represents a physical barrier that contributes to immune evasion in the cell niche (193).

Another important alteration in the leukemic TME is the increased levels of anti-inflammatory and immunosuppressive cytokines, such as IL-10 and TGF- $\beta$, and the high expression of PD-1 and TIGIT, which contribute to tumor progression and immune evasion $(43,47,55,194)$. IL- 1, IFN- $\gamma$, TNF- $\alpha$, and HLA$\mathrm{G}$ in the BM-TME may induce immune tolerance and then ALL recurrence. Additionally, overexpression in BM-TME of chemotactic cytokines such as CXCL12/CXCR4 and CCL25/ CCR9 (produced by stromal cells in the BM) has a role in ALL and influences the outcomes and chemoresistance. Thus, targeting the chemokine axis could significantly reduce tumor burden in ALL (182).

It is well known that the immunosuppressive microenvironment surrounding tumor cells represents a key cause of treatment failure; therefore, BM-TME is the central target for reprogramming the immune system in ALL and other hematological malignancies.

\section{INTO THE FRONTLINE OF ALL TREATMENT: TARGETING THE IMMUNE CELLS}

Initial ALL treatment comprises induction, consolidation, and long-term maintenance therapy. The backbone of ALL therapy is chemotherapy using drugs developed during the 1950s and 1960s focused on leukemic cell eradication, normal hematopoiesis restoration, and prevention of "sanctuary site" invasion, relapse, and death $(195,196)$. Chemotherapy has achieved considerable success in ALL survival (9); however, relapse occurring in approximately $20 \%$ of patients with ALL is the main obstacle in improving the OS rates. Adult patients with ALL have a higher risk of relapse than pediatric patients, and the protocols used (adapted from pediatric protocols) reach less than $50 \%$ of the success rate and have lower minimal residual disease negative rates after induction therapy (197). Allogeneic hematopoietic stem cell transplantation (alloHSCT) has been an effective anti-leukemic therapy for patients with ALL $(198,199)$ but is a highly toxic therapy, and disease recurrences can occur within the time of immunosuppressive treatment $(200,201)$.

Over the last two decades, multiple studies have attempted to improve the OS of patients with ALL by incorporating new agents into the treatment protocols and exploiting the immune response against leukemia cells. Targeting of tumor cells is a promising therapeutic approach. Antibody-based therapeutic strategies are being developed to select cells of the immune system, enhance anti-tumor immune response, and reduce damage to normal tissues $(93,202)$. T cell signaling pathway inhibition (particularly PD-L1/PD-1), immune cell regulation, and the prevention of tryptophan depletion by indoeamine-2,3dioxygenase are the most well-studied immunosuppressive mechanisms in liquid tumors (93). Nevertheless, few trials based on these pathways have been described for ALL treatment. Monoclonal antibodies (mAbs), immune checkpoint blockers, CAR T cells, and bispecific T-cell engagers (BiTEs) are currently used in ALL treatments approved by the USA Food and Drug Administration (FDA) (203-205). Approaches using adoptive $\mathrm{T}$ cell therapy (ACT) and tumor neoantigens are under investigation (93).

\section{Monoclonal Antibodies}

Antibodies are the basis for many new anti-cancer treatment strategies due to their immunomodulatory properties and capacity to promote the induction of anti-tumor immune responses. These antibodies target self-tumor antigens or the TME to inhibit tumor growth by increasing host immune responses to antigens expressed by the tumor itself or by reducing pro-tumorigenic factors generated in the tumor stroma (206). CTLA-4-specific mAbs have been used in human cancers, such as melanoma (206). Using the antiCTLA-4 mAb (ipilimumab) in combination with IgG4 mAb (nivolumab), which disrupts the interaction between PD-1 and PD-L1/PD-L2, in patients with relapsed/refractory cHL, nonHodgkin lymphoma, or multiple myeloma showed no significant improvement in efficacy over single-agent nivolumab (207). The anti-PD-1 anti-leukemic treatment is based on the maintenance and expansion of tumor-specific memory $\mathrm{T}$ cells and NK cell activation. This approach has been explored in diverse tumors, including relapsed/refractory lymphoid malignancies; however, its clinical application in ALL remains unknown. In ALL, CD-38 and CD-52 have been identified as target antigens of mAbs for the treatment of relapsed $\mathrm{T}$ cell ALL. Currently, there are ongoing clinical trials testing the efficacy of anti-CD38 mAbs (isatuximab and daratumumab) and anti-CD52 $\mathrm{mAbs}$ (alemtuzumab) with favorable results for better disease prognosis (127).

\section{Bispecific T Cell Engagers}

BiTEs are bispecific recombinant glycoproteins with two singlechain variable fragments (scFvs) connected by a flexible linker, whose targets are membrane molecules (costimulators, coinhibitors, adhesion, etc.) from both $\mathrm{T}$ cells and malignant cells. BiTEs favor immune responses by creating an immune synapse among tumor antigens and $\mathrm{T}$ cells (204). The distribution of BiTEs depends on factors such as the diffusion of the vascular endothelium, laminar flux rate, and interaction with the target. Blinatumomab (anti-CD19/anti-CD3; AMG103) is a BiTE that binds to CD3+ lymphocyte $\mathrm{T}$ and CD19+ $\mathrm{B}$ lymphocytes. Although blinatumomab induces selective lysis of tumoral cells, its half-life is short, and constant administration is necessary for effect maintenance. The Children's Oncology 
Group has incorporated blinatumomab in clinical trials in patients with B cell ALL with a standard risk (1-9.99 years and leukocyte count $<50,000 / \mathrm{ml}$ ) classification. Good results and acceptable toxicity were observed; in addition, half of the population had a significant twofold improvement in median OS compared to patients with standard chemotherapy regimens (208).

Studies in patients with relapse/refractory pre-B cell ALL indicate that Treg proportion could determine the prognosis of blinatumomab treatment. It was observed that blinatumomab responders had a lower percentage of Tregs (4.82\%) in peripheral blood compared to non-responders (10.25\%). Additionally, the restoration of the activated $\mathrm{T}$ cell population was detected after the in vitro depletion of Tregs in leukemic blasts, thus highlighting the regulatory role of Tregs in the development of the immune response in ALL (209).

The main disadvantage of BiTEs is the induction of cytokine release syndrome (CRS) through proinflammatory cytokines and aplasia of lymphocytes B (205). Although collateral effects in clinical assays with blinatumomab have been reported (fever, nausea, headache, neurological, and hepatic adverse effects), a lower percentage of minimal residual disease in patients treated with blinatumomab in contrast to patients with high-risk ALL treated with conventional regimens was reported $(204,208,210)$.

\section{CAR T Cells}

CAR is a synthetic construct formed by an extracellular scFvc (that recognizes the tumor antigen) fused to a transmembrane domain and to intracellular activating/co-stimulator motives (CD3 $\zeta$, CD28, 4-1BB) $(204,211-213)$. CAR is transduced to $\mathrm{T}$ cells (CAR $\mathrm{T}$ cell), and after the recognition of the tumoral antigen, it promotes a cytotoxic effect on the target cell (205). It has been reported that CAR T cells act independently of HLA recognition. Therefore, this approach could be used in different cases to overcome the lower HLA density of ALL malignant cells. Furthermore, it is feasible to use CD4+ T and CD8+ T cells to generate CAR T cells, which increases the effector and cytotoxic potential of $\mathrm{T}$ cells (213).

CAR T cells have recently been approved by the FDA to treat patients with leukemia and lymphoma (203-205), and several clinical trials of CD19 CAR T cell therapy are being carried out in ALL relapse patients, which have shown favorable results with remission after 6 months in up to $90 \%$ of the patients, with $78 \%$ OS and 67\% event-free survival (214). However, in a group of refractory/relapsed patients with B cell ALL, CD22 CAR T cell therapy treatment achieved a complete remission of $70.5 \%$ in comparison with those previously treated with CD19 CAR T cells without success. CD22 CAR T cell-treated patients only exhibited a moderate grade of CRS and neurotoxicity, and better results were observed in patients undergoing alloHSCT (215). An important advantage of CAR T cells is their capacity to interact with malignant cells displaying different antigens, such as CD19, CD20, and CD22 (212).

Although CAR T cell implementation in B cell ALL has obtained favorable results, its implementation in T cell ALL presents limitations because CAR T cells and malignant T cells share similar expression profiles of target antigens, which gives rise to a non-specific cytotoxic activity incapable of discriminating CAR $\mathrm{T}$ cells from malignant $\mathrm{T}$ cells, leading to T cell aplasia and eventual immunodeficiency. Notwithstanding, the identification of antigens, such as CD4, CD5, and CD7, on T cell ALL shows promise for the use of CAR T cell technology, the clinical trials of which are ongoing (127).

Limitations of CAR T cell therapy in ALL involve the following (1): poor expansion and limited persistence in vivo caused by defects in the design and manufacturing of CAR T cell therapy (2), internalization of the CD19 glycoprotein and resurgence in tumor cells (3), toxicity (CAR $\mathrm{T}$ cells present numerous cellular interactions that could promote the cytokinemediated systemic inflammatory response), and (4) aplasia of B cells and humoral deficiency that might promote infections (204, 205, 216).

\section{Adoptive T Cell Therapy Using Tumor Neoantigens}

ACT is based on TIL expansion and infusion in patients following lymphodepletion. ACT aims to generate a robust immune-mediated antitumor response via infusion of ex vivomanipulated T cells. Studies have suggested that clinical outcomes correlate with tumor mutational and neoantigen load (217-219). Although ALL has been described as a malignancy with low mutational load, a recent analysis reported that it is possible to obtain immunodominant neoantigens that could be used to develop neoepitope-CD8+ T cells and treat patients with $\operatorname{ALL}(83,220)$. To explore the effectiveness of this strategy, 36 putative neoantigens from the ETV6-RUNX1 fusion were tested, and 31 neoantigens were immunogenic. The co-culture of HLA-specific APCs with neoepitopes and isolated CD8+ tumor-infiltrating lymphocytes results in TNF- $\alpha$ and IFN- $\gamma$ production. Therefore, this strategy provides a possibility to consider the adoptive transfer of neoepitope-CD8+ $\mathrm{T}$ cells as immunotherapy in leukemia and could be used in the consolidation phase or subsequent treatment (83).

\section{Activation of Necroptosis}

The suppression of cell proliferation in leukemic lineages has significant challenges. On one hand, mAb treatment ablates the main elements of the adaptive immune response, including $\mathrm{T}$ and B cells, which could favor infection burst or immunemediated disease development $(221,222)$. On the other hand, to increase tumor-specific $\mathrm{T}$ cell responses, it is necessary to promote leukemic cell immunogenicity. To date, the primary goal of several research groups has been to promote apoptosis in malignant cells; however, this type of cell death is immunetolerogenic. Recent studies have shown that a new class of targeted drugs (second mitochondrial activator of caspases, SMAC) antagonizes diverse anti-apoptotic proteins (inhibitor of apoptosis proteins) and, in combination with dexamethasone, promotes increased immunogenic cell death (necroptosis) in ALL $(223,224)$. Necroptosis is a regulated inflammatory mode of cell death that is caspase-independent and presents highly regulated necrotic features (225). Necroptosis produces the release of DAMPs and proinflammatory cytokines, allowing a 
better cytotoxic function by tumor-specific T cells (225-227). The activation of necroptosis has been explored as an antileukemic therapy, and several SMAC mimetic compounds are currently in phase I or II clinical trials to treat hematological malignancies, including ALL $(225,228)$. The leading problem with active necroptosis in ALL therapy is its potential to induce immunogenicity. Observations from solid tumors suggest that necroptosis is not always pro-inflammatory or immunogenic; however, there are no reports of necroptosis in $\operatorname{ALL}(223,229)$.

\section{CONCLUSION}

Despite defined treatment protocols, leukemia remains a global health problem due to high relapse and treatment failure rates. ALL studies suggest that immune response evasion by leukemic cells could promote malignant cell proliferation and invasion. The identification of leukemic cell strategies to deactivate immune cells and induce an immunosuppressive TME to resist apoptosis has been suggested to have potential implications in the field of personalized immunotherapy for ALL-for example, the infusion of co-stimulatory adapted CAR T cells to increase cytotoxic T cell responses is a current option for ALL treatment. The infusion of neoepitope-specific ALL cells to increase the $\mathrm{MHC}$ response is also a potential alternative. Among the treatments for patients with ALL, the induction of leukemic

\section{REFERENCES}

1. Bray F, Ferlay J, Soerjomataram I, Siegel RL, Torre LA, Jemal A. Global Cancer Statistics 2018: GLOBOCAN Estimates of Incidence and Mortality Worldwide for 36 Cancers in 185 Countries. CA Cancer J Clin (2018) 68 (6):394-424. doi: 10.3322/caac.21492

2. Miranda-Filho A, Pineros M, Ferlay J, Soerjomataram I, Monnereau A, Bray F. Epidemiological Patterns of Leukaemia in 184 Countries: A Population-Based Study. Lancet Haematol (2018) 5(1):e14-24. doi: 10.1016/S2352-3026(17)30232-6

3. Paul S, Rausch CR, Nasnas PE, Kantarjian H, Jabbour EJ. Treatment of Relapsed/Refractory Acute Lymphoblastic Leukemia. Clin Adv Hematol Oncol (2019) 17(3):166-75.

4. Sung H, Ferlay J, Siegel RL, Laversanne M, Soerjomataram I, Jemal A, et al. Global Cancer Statistics 2020: GLOBOCAN Estimates of Incidence and Mortality Worldwide for 36 Cancers in 185 Countries. CA Cancer J Clin (2021) 71(3):209-49. doi: 10.3322/caac.21660

5. Paul S, Kantarjian H, Jabbour EJ. Adult Acute Lymphoblastic Leukemia. Mayo Clin Proc (2016) 91(11):1645-66. doi: 10.1016/j.mayocp.2016.09.010

6. Borowitz MJ, Devidas M, Hunger SP, Bowman WP, Carroll AJ, Carroll WL, et al. Clinical Significance of Minimal Residual Disease in Childhood Acute Lymphoblastic Leukemia and Its Relationship to Other Prognostic Factors: A Children's Oncology Group Study. Blood (2008) 111(12):5477-85. doi: 10.1182/blood-2008-01-132837

7. Abbasi S, Maleha F, Shobaki M. Acute Lymphoblastic Leukemia Experience: Epidemiology and Outcome of Two Different Regimens. Mediterr J Hematol Infect Dis (2013) 5(1):e2013024. doi: 10.4084/MJHID.2013.024

8. Solomon B, Parihar N, Ayodele L, Hughes M. Hematology \& Hematological Oncology. In: Journal of Blood Disorders \& Transfusion. Las Vegas, USA (2017). p. 9864. Available from: https://www.omicsonline.org/conferenceproceedings/hematology-2017-scientifictracks-abstracts.digital.

9. Dinner S, Gurbuxani S, Jain N, Stock W. Acute Lymphoblastic Leukemia in Adults. In: Hoffman R, Benz E, et al, editors. Hematology. Las Vegas, USA: Elsevier (2018). p. 1029.e2- 54.e2. cells to become immunogenic is a promising alternative because it promotes an immunogenic microenvironment and influences direct malignant cell elimination. Further research into the immune evasion mechanisms underlying ALL development and progression is required to gain knowledge on the molecular and cellular leukemogenesis mechanisms, which could contribute to the design of new anti-ALL therapies.

\section{AUTHOR CONTRIBUTIONS}

SJ-M, IA-U, and CP-A participated in the preparation of the original draft. JR-B and AH-M participated in revision and editing. SJ-M took charge of conceptualization, supervision, and funding acquisition. All authors contributed to the article and approved the submitted version.

\section{FUNDING}

This work was supported by the Consejo Nacional de Ciencia y Tecnología (CONACyT, Investigación en Fronteras de la Ciencia -2016-01-2119) and by the National Institute of Genomic Medicine (01/2018/I and 19/2019/I). ISA-U and CJP-A were supported by CONACyT with the scholarships CVU 324181 and 821714 , respectively.

10. Rivera-Luna R, Velasco-Hidalgo L, Zapata-Tarres M, Cardenas-Cardos R, Aguilar-Ortiz MR. Current Outlook of Childhood Cancer Epidemiology in a Middle-Income Country Under a Public Health Insurance Program. Pediatr Hematol Oncol (2017) 34(1):43-50. doi: 10.1080/08880018.2016.1276236

11. Magrath I, Steliarova-Foucher E, Epelman S, Ribeiro RC, Harif M, Li CK, et al. Paediatric Cancer in Low-Income and Middle-Income Countries. Lancet Oncol (2013) 14(3):e104-16. doi: 10.1016/S1470-2045(13)70008-1

12. Jimenez-Hernandez E, Jaimes-Reyes EZ, Arellano-Galindo J, GarciaJimenez X, Tiznado-Garcia HM, Duenas-Gonzalez MT, et al. Survival of Mexican Children With Acute Lymphoblastic Leukaemia Under Treatment With the Protocol From the Dana-Farber Cancer Institute 00-01. BioMed Res Int (2015) 2015:576950. doi: 10.1155/2015/576950

13. Martin-Trejo JA, Nunez-Enriquez JC, Fajardo-Gutierrez A, Medina-Sanson A, Flores-Lujano J, Jimenez-Hernandez E, et al. Early Mortality in Children With Acute Lymphoblastic Leukemia in a Developing Country: The Role of Malnutrition at Diagnosis. A Multicenter Cohort MIGICCL Study. Leuk Lymphoma (2017) 58(4):898-908. doi: 10.1080/10428194.2016.1219904

14. Moricke A, Zimmermann M, Valsecchi MG, Stanulla M, Biondi A, Mann G, et al. Dexamethasone vs Prednisone in Induction Treatment of Pediatric ALL: Results of the Randomized Trial AIEOP-BFM ALL 2000. Blood (2016) 127(17):2101-12. doi: 10.1182/blood-2015-09-670729

15. Advani A. Acute Lymphoblastic Leukemia (ALL). Best Pract Res Clin Haematol (2017) 30(3):173-4. doi: 10.1016/j.beha.2017.07.004

16. O’Dwyer KM, Liesveld JL. Philadelphia Chromosome Negative B-Cell Acute Lymphoblastic Leukemia in Older Adults: Current Treatment and Novel Therapies. Best Pract Res Clin Haematol (2017) 30(3):184-92. doi: 10.1016/ j.beha.2017.08.001

17. Jain P, Korula A, Deshpande P, Pn N, Abu Alex A, Abraham A, et al. Adult Acute Lymphoblastic Leukemia: Limitations of Intensification of Therapy in a Developing Country. J Glob Oncol (2018) 4:1-12. doi: 10.1200/ JGO.17.00014

18. Oskarsson T, Soderhall S, Arvidson J, Forestier E, Montgomery S, Bottai M, et al. Relapsed Childhood Acute Lymphoblastic Leukemia in the Nordic 
Countries: Prognostic Factors, Treatment and Outcome. Haematologica (2016) 101(1):68-76. doi: 10.3324/haematol.2015.131680

19. Oriol A, Vives S, Hernandez-Rivas JM, Tormo M, Heras I, Rivas C, et al. Outcome After Relapse of Acute Lymphoblastic Leukemia in Adult Patients Included in Four Consecutive Risk-Adapted Trials by the PETHEMA Study Group. Haematologica (2010) 95(4):589-96. doi: 10.3324/haematol.2009.014274

20. Locatelli F, Schrappe M, Bernardo ME, Rutella S. How I Treat Relapsed Childhood Acute Lymphoblastic Leukemia. Blood (2012) 120(14):2807-16. doi: 10.1182/blood-2012-02-265884

21. DeAngelo DJ, Jabbour E, Advani A. Recent Advances in Managing Acute Lymphoblastic Leukemia. Am Soc Clin Oncol Educ Book (2020) 40:330-42. doi: 10.1200/EDBK_280175

22. Parker C, Waters R, Leighton C, Hancock J, Sutton R, Moorman AV, et al. Effect of Mitoxantrone on Outcome of Children With First Relapse of Acute Lymphoblastic Leukaemia (ALL R3): An Open-Label Randomised Trial. Lancet (2010) 376(9757):2009-17. doi: 10.1016/S0140-6736(10)62002-8

23. Kuhlen M, Willasch AM, Dalle JH, Wachowiak J, Yaniv I, Ifversen M, et al. Outcome of Relapse After Allogeneic HSCT in Children With ALL Enrolled in the ALL-SCT 2003/2007 Trial. Br J Haematol (2018) 180(1):82-9. doi: 10.1111/bjh.14965

24. Kuhlen M, Klusmann JH, Hoell JI. Molecular Approaches to Treating Pediatric Leukemias. Front Pediatr (2019) 7:368. doi: 10.3389/ fped.2019.00368

25. Phelan KW, Advani AS. Novel Therapies in Acute Lymphoblastic Leukemia. Curr Hematol Malig Rep (2018) 13(4):289-99. doi: 10.1007/s11899-018-0457-7

26. Zhang MY, Liu SL, Huang WL, Tang DB, Zheng WW, Zhou N, et al. Bromodomains and Extra-Terminal (BET) Inhibitor JQ1 Suppresses Proliferation of Acute Lymphocytic Leukemia by Inhibiting C-MycMediated Glycolysis. Med Sci Monit (2020) 26:e923411. doi: 10.12659/ MSM.923411

27. Inaba $\mathrm{H}$, Pui $\mathrm{CH}$. Immunotherapy in Pediatric Acute Lymphoblastic Leukemia. Cancer Metastasis Rev (2019) 38(4):595-610. doi: 10.1007/ s10555-019-09834-0

28. Witkowski MT, Lasry A, Carroll WL, Aifantis I. Immune-Based Therapies in Acute Leukemia. Trends Cancer (2019) 5(10):604-18. doi: 10.1016/ j.trecan.2019.07.009

29. Blair GE, Cook GP. Cancer and the Immune System: An Overview. Oncogene (2008) 27(45):5868. doi: 10.1038/onc.2008.277

30. Abbott M, Ustoyev Y. Cancer and the Immune System: The History and Background of Immunotherapy. Semin Oncol Nurs (2019) 35(5):150923. doi: 10.1016/j.soncn.2019.08.002

31. Beatty GL, Gladney WL. Immune Escape Mechanisms as a Guide for Cancer Immunotherapy. Clin Cancer Res (2015) 21(4):687-92. doi: 10.1158/10780432.CCR-14-1860

32. Swann JB, Smyth MJ. Immune Surveillance of Tumors. J Clin Invest (2007) 117(5):1137-46. doi: 10.1172/JCI31405

33. Ramirez-Ramirez D, Padilla-Castaneda S, Galan-Enriquez CS, Vadillo E, Prieto-Chavez JL, Jimenez-Hernandez E, et al. CRTAM(+) NK Cells Endowed With Suppressor Properties Arise in Leukemic Bone Marrow. J Leukoc Biol (2019) 105(5):999-1013. doi: 10.1002/JLB.MA0618-231R

34. Kearney CJ, Vervoort SJ, Hogg SJ, Ramsbottom KM, Freeman AJ, Lalaoui N, et al. Tumor Immune Evasion Arises Through Loss of TNF Sensitivity. Sci Immunol (2018) 3(23):1-14. doi: 10.1126/sciimmunol.aar3451

35. Pardoll D. Cancer and the Immune System: Basic Concepts and Targets for Intervention. Semin Oncol (2015) 42(4):523-38. doi: 10.1053/j.seminoncol. 2015.05.003

36. Sharma P, Hu-Lieskovan S, Wargo JA, Ribas A. Primary, Adaptive, and Acquired Resistance to Cancer Immunotherapy. Cell (2017) 168(4):707-23. doi: 10.1016/j.cell.2017.01.017

37. Cheng M, Chen Y, Xiao W, Sun R, Tian Z. NK Cell-Based Immunotherapy for Malignant Diseases. Cell Mol Immunol (2013) 10(3):230-52. doi: $10.1038 / \mathrm{cmi} .2013 .10$

38. Jorgovanovic D, Song M, Wang L, Zhang Y. Roles of IFN-Gamma in Tumor Progression and Regression: A Review. Biomark Res (2020) 8:49. doi: 10.1186/s40364-020-00228-x

39. Takeda K, Nakayama M, Hayakawa Y, Kojima Y, Ikeda H, Imai N, et al. IFN-Gamma Is Required for Cytotoxic T Cell-Dependent Cancer Genome Immunoediting. Nat Commun (2017) 8:14607. doi: 10.1038/ncomms14607
40. Aqbi HF, Wallace M, Sappal S, Payne KK, Manjili MH. IFN-Gamma Orchestrates Tumor Elimination, Tumor Dormancy, Tumor Escape, and Progression. J Leukoc Biol (2018) 22:1-5. doi: 10.1002/JLB.5MIR0917-351R

41. Crispin JC, Tsokos GC. Cancer Immunosurveillance by CD8 T Cells. F1000Res (2020) 9:1-7. doi: 10.12688/f1000research.21150.1

42. Philip M, Schietinger A. CD8(+) T Cell Differentiation and Dysfunction in Cancer. Nat Rev Immunol (2021). doi: 10.1038/s41577-021-00574-3

43. Anderson KG, Stromnes IM, Greenberg PD. Obstacles Posed by the Tumor Microenvironment to T Cell Activity: A Case for Synergistic Therapies. Cancer Cell (2017) 31(3):311-25. doi: 10.1016/j.ccell.2017.02.008

44. Teng MW, Galon J, Fridman WH, Smyth MJ. From Mice to Humans: Developments in Cancer Immunoediting. J Clin Invest (2015) 125(9):333846. doi: $10.1172 / \mathrm{JCI} 80004$

45. Vinay DS, Ryan EP, Pawelec G, Talib WH, Stagg J, Elkord E, et al. Immune Evasion in Cancer: Mechanistic Basis and Therapeutic Strategies. Semin Cancer Biol (2015) 35 Suppl:S185-98. doi: 10.1016/j.semcancer.2015.03.004

46. Tugues S, Burkhard SH, Ohs I, Vrohlings M, Nussbaum K, Vom Berg J, et al. New Insights Into IL-12-Mediated Tumor Suppression. Cell Death Differ (2015) 22(2):237-46. doi: 10.1038/cdd.2014.134

47. Cassim S, Pouyssegur J. Tumor Microenvironment: A Metabolic Player That Shapes the Immune Response. Int J Mol Sci (2019) 21(1):1-23. doi: 10.3390/ ijms 21010157

48. Dunn GP, Old LJ, Schreiber RD. The Immunobiology of Cancer Immunosurveillance and Immunoediting. Immunity (2004) 21(2):137-48. doi: 10.1016/j.immuni.2004.07.017

49. Romero I, Garrido C, Algarra I, Collado A, Garrido F, Garcia-Lora AM. T Lymphocytes Restrain Spontaneous Metastases in Permanent Dormancy. Cancer Res (2014) 74(7):1958-68. doi: 10.1158/0008-5472.CAN-13-2084

50. Wang HF, Wang SS, Huang MC, Liang XH, Tang YJ, Tang YL. Targeting Immune-Mediated Dormancy: A Promising Treatment of Cancer. Front Oncol (2019) 9:498. doi: 10.3389/fonc.2019.00498

51. Palucka AK, Coussens LM. The Basis of Oncoimmunology. Cell (2016) 164 (6):1233-47. doi: 10.1016/j.cell.2016.01.049

52. Chalmers ZR, Connelly CF, Fabrizio D, Gay L, Ali SM, Ennis R, et al. Analysis of 100,000 Human Cancer Genomes Reveals the Landscape of Tumor Mutational Burden. Genome Med (2017) 9(1):34. doi: 10.1186/ s13073-017-0424-2

53. Chen J, Zhang H, Zhou L, Hu Y, Li M, He Y, et al. Enhancing the Efficacy of Tumor Vaccines Based on Immune Evasion Mechanisms. Front Oncol (2020) 10:584367. doi: 10.3389/fonc.2020.584367

54. Zheng Y, Delgoffe GM, Meyer CF, Chan W, Powell JD. Anergic T Cells are Metabolically Anergic. J Immunol (2009) 183(10):6095-101. doi: 10.4049/ jimmunol.0803510

55. Dander E, Palmi C, D’Amico G, Cazzaniga G. The Bone Marrow Niche in BCell Acute Lymphoblastic Leukemia: The Role of Microenvironment From Pre-Leukemia to Overt Leukemia. Int J Mol Sci (2021) 22(9):1-24. doi: 10.3390/ijms22094426

56. Howie D, Ten Bokum A, Necula AS, Cobbold SP, Waldmann H. The Role of Lipid Metabolism in T Lymphocyte Differentiation and Survival. Front Immunol (2017) 8:1949. doi: 10.3389/fimmu.2017.01949

57. Noguchi T, Ward JP, Gubin MM, Arthur CD, Lee SH, Hundal J, et al. Temporally Distinct PD-L1 Expression by Tumor and Host Cells Contributes to Immune Escape. Cancer Immunol Res (2017) 5(2):106-17. doi: 10.1158/2326-6066.CIR-16-0391

58. Jiang X, Wang J, Deng X, Xiong F, Ge J, Xiang B, et al. Role of the Tumor Microenvironment in PD-L1/PD-1-Mediated Tumor Immune Escape. Mol Cancer (2019) 18(1):10. doi: 10.1186/s12943-018-0928-4

59. Torelli GF, Peragine N, Raponi S, Pagliara D, De Propris MS, Vitale A, et al. Recognition of Adult and Pediatric Acute Lymphoblastic Leukemia Blasts by Natural Killer Cells. Haematologica (2014) 99(7):1248-54. doi: 10.3324/ haematol.2013.101931

60. Alkhouly N, Shehata I, Ahmed MB, Shehata H, Hassan S, Ibrahim T. HLA-G Expression in Acute Lymphoblastic Leukemia: A Significant Prognostic Tumor Biomarker. Med Oncol (2013) 30(1):460. doi: 10.1007/s12032-013$0460-8$

61. Valenzuela-Vazquez L, Nunez-Enriquez JC, Sanchez-Herrera J, JimenezHernandez E, Martin-Trejo JA, Espinoza-Hernandez LE, et al. Functional Characterization of NK Cells in Mexican Pediatric Patients With Acute 
Lymphoblastic Leukemia: Report From the Mexican Interinstitutional Group for the Identification of the Causes of Childhood Leukemia. PloS One (2020) 15(1):e0227314. doi: 10.1371/journal.pone.0227314

62. Montironi C, Munoz-Pinedo C, Eldering E. Hematopoietic Versus Solid Cancers and T Cell Dysfunction: Looking for Similarities and Distinctions. Cancers (Basel) (2021) 13(2):1-20. doi: 10.3390/cancers13020284

63. Xu J, Xu W, Xuan Y, Liu Z, Sun Q, Lan C. Pancreatic Cancer Progression Is Regulated by IPO7/p53/LncRNA MALAT1/MiR-129-5p Positive Feedback Loop. Front Cell Dev Biol (2021) 9:630262. doi: 10.3389/fcell.2021.630262

64. Shimada K, Yoshida K, Suzuki Y, Iriyama C, Inoue Y, Sanada M, et al. Frequent Genetic Alterations in Immune Checkpoint-Related Genes in Intravascular Large B-Cell Lymphoma. Blood (2021) 137(11):1491-502. doi: 10.1182/blood.2020007245

65. Rosenthal R, Cadieux EL, Salgado R, Bakir MA, Moore DA, Hiley CT, et al. Neoantigen-Directed Immune Escape in Lung Cancer Evolution. Nature (2019) 567(7749):479-85. doi: 10.1038/s41586-019-1032-7

66. Vidotto T, Nersesian S, Graham C, Siemens DR, Koti M. DNA Damage Repair Gene Mutations and Their Association With Tumor Immune Regulatory Gene Expression in Muscle Invasive Bladder Cancer Subtypes. J Immunother Cancer (2019) 7(1):148. doi: 10.1186/s40425-019-0619-8

67. Kobayashi Y, Lim SO, Yamaguchi H. Oncogenic Signaling Pathways Associated With Immune Evasion and Resistance to Immune Checkpoint Inhibitors in Cancer. Semin Cancer Biol (2020) 65:51-64. doi: 10.1016/ j.semcancer.2019.11.011

68. Meyer S, Handke D, Mueller A, Biehl K, Kreuz M, Bukur J, et al. Distinct Molecular Mechanisms of Altered HLA Class II Expression in Malignant Melanoma. Cancers (Basel) (2021) 13(15):1-18. doi: 10.3390/cancers13153907

69. Xu HH, Gan J, Xu DP, Li L, Yan WH. Comprehensive Transcriptomic Analysis Reveals the Role of the Immune Checkpoint HLA-G Molecule in Cancers. Front Immunol (2021) 12:614773. doi: 10.3389/fimmu.2021.614773

70. Mimura K, Teh JL, Okayama H, Shiraishi K, Kua LF, Koh V, et al. PD-L1 Expression is Mainly Regulated by Interferon Gamma Associated With JAKSTAT Pathway in Gastric Cancer. Cancer Sci (2018) 109(1):43-53. doi: $10.1111 /$ cas. 13424

71. Sivori S, Della Chiesa M, Carlomagno S, Quatrini L, Munari E, Vacca P, et al. Inhibitory Receptors and Checkpoints in Human NK Cells, Implications for the Immunotherapy of Cancer. Front Immunol (2020) 11:2156. doi: 10.3389/ fimmu.2020.02156

72. Jansen JA, Omuro A, Lucca LE. T Cell Dysfunction in Glioblastoma: A Barrier and an Opportunity for the Development of Successful Immunotherapies. Curr Opin Neurol (2021). doi: 10.1097/WCO. 0000000000000988

73. Vlachonikola E, Stamatopoulos K, Chatzidimitriou A. T Cell Defects and Immunotherapy in Chronic Lymphocytic Leukemia. Cancers (Basel) (2021) 13(13):1-16. doi: 10.3390/cancers13133255

74. Qiu Y, Yang Y, Yang R, Liu C, Hsu JM, Jiang Z, et al. Activated T CellDerived Exosomal PD-1 Attenuates PD-L1-Induced Immune Dysfunction in Triple-Negative Breast Cancer. Oncogene (2021) 40(31):4992-5001. doi: 10.1038/s41388-021-01896-1

75. Hung MH, Lee JS, Ma C, Diggs LP, Heinrich S, Chang CW, et al. Tumor Methionine Metabolism Drives T-Cell Exhaustion in Hepatocellular Carcinoma. Nat Commun (2021) 12(1):1455. doi: 10.1038/s41467-02121804-1

76. Abiko K, Mandai M, Hamanishi J, Yoshioka Y, Matsumura N, Baba T, et al. PD-L1 on Tumor Cells is Induced in Ascites and Promotes Peritoneal Dissemination of Ovarian Cancer Through CTL Dysfunction. Clin Cancer Res (2013) 19(6):1363-74. doi: 10.1158/1078-0432.CCR-12-2199

77. Jo S, Lee JH, Mattei JJ, Barrett DM, van den Elzen P, Grupp SA, et al. Generation of a Multi-Antigen-Directed Immune Response for Durable Control of Acute Lymphoblastic Leukemia. Leukemia (2018) 32(2):574. doi: 10.1038/leu.2017.312

78. Kebelmann-Betzing C, Korner G, Badiali L, Buchwald D, Moricke A, Korte A, et al. Characterization of Cytokine, Growth Factor Receptor, Costimulatory and Adhesion Molecule Expression Patterns of Bone Marrow Blasts in Relapsed Childhood B Cell Precursor All. Cytokine (2001) 13(1):39-50. doi: 10.1006/cyto.2000.0794

79. Luczynski W, Stasiak-Barmuta A, Ilendo E, Kovalchuk O, Krawczuk-Rybak M, Malinowska I, et al. Low Expression of Costimulatory Molecules and
mRNA for Cytokines are Important Mechanisms of Immunosuppression in Acute Lymphoblastic Leukemia in Children? Neoplasma (2006) 53(4):301-4.

80. D’Amico G, Vulcano M, Bugarin C, Bianchi G, Pirovano G, Bonamino M, et al. CD40 Activation of BCP-ALL Cells Generates IL-10-Producing, IL-12Defective APCs That Induce Allogeneic T-Cell Anergy. Blood (2004) 104 (3):744-51. doi: 10.1182/blood-2003-11-3762

81. Feng YY, Griffith OL, Griffith M. Clinical Implications of Neoepitope Landscapes for Adult and Pediatric Cancers. Genome Med (2017) 9(1):77. doi: 10.1186/s13073-017-0470-9

82. Zamora AE, Crawford JC, Thomas PG. Hitting the Target: How T Cells Detect and Eliminate Tumors. J Immunol (2018) 200(2):392-9. doi: 10.4049/ jimmunol.1701413

83. Zamora AE, Crawford JC, Allen EK, Guo XJ, Bakke J, Carter RA, et al. Pediatric Patients With Acute Lymphoblastic Leukemia Generate Abundant and Functional Neoantigen-Specific CD8(+) T Cell Responses. Sci Transl Med (2019) 11(498):1-29. doi: 10.1126/scitranslmed.aat8549

84. Chang TC, Carter RA, Li Y, Li Y, Wang H, Edmonson MN, et al. The Neoepitope Landscape in Pediatric Cancers. Genome Med (2017) 9(1):78. doi: 10.1186/s13073-017-0468-3

85. Curran EK, Godfrey J, Kline J. Mechanisms of Immune Tolerance in Leukemia and Lymphoma. Trends Immunol (2017) 38(7):513-25. doi: 10.1016/j.it.2017.04.004

86. Vardhana S, Younes A. The Immune Microenvironment in Hodgkin Lymphoma: T Cells, B Cells, and Immune Checkpoints. Haematologica (2016) 101(7):794-802. doi: 10.3324/haematol.2015.132761

87. Cardoso AA, Schultze JL, Boussiotis VA, Freeman GJ, Seamon MJ, Laszlo S, et al. Pre-B Acute Lymphoblastic Leukemia Cells may Induce T-Cell Anergy to Alloantigen. Blood (1996) 88(1):41-8. doi: 10.1182/blood.V88.1.41.41

88. Spencer HC, Masaba SC, Kiaraho D. Sensitivity of Plasmodium Falciparum Isolates to Chloroquine in Kisumu and Malindi, Kenya. Am J Trop Med Hyg (1982) 31(5):902-6. doi: 10.4269/ajtmh.1982.31.902

89. Bien E, Balcerska A, Adamkiewicz-Drozynska E, Rapala M, Krawczyk M, Stepinski J. Pre-Treatment Serum Levels of Interleukin-10, Interleukin-12 and Their Ratio Predict Response to Therapy and Probability of Event-Free and Overall Survival in Childhood Soft Tissue Sarcomas, Hodgkin's Lymphomas and Acute Lymphoblastic Leukemias. Clin Biochem (2009) 42 (10-11):1144-57. doi: 10.1016/j.clinbiochem.2009.04.004

90. Knaus HA, Kanakry CG, Luznik L, Gojo I. Immunomodulatory Drugs: Immune Checkpoint Agents in Acute Leukemia. Curr Drug Targets (2017) 18(3):315-31. doi: 10.2174/1389450116666150518095346

91. de Deus DM, Lugo KA, Muniz MT. Influence of IL10 (G1082A) and TNFalpha (G308A) Polymorphisms on the Survival of Pediatric Patients With ALL. Leuk Res Treat (2012) 2012:692348. doi: 10.1155/2012/692348

92. Hiroki CH, Amarante MK, Petenuci DL, Sakaguchi AY, Trigo FC, Watanabe MA, et al. IL-10 Gene Polymorphism and Influence of Chemotherapy on Cytokine Plasma Levels in Childhood Acute Lymphoblastic Leukemia Patients: IL-10 Polymorphism and Plasma Levels in Leukemia Patients. Blood Cells Mol Dis (2015) 55(2):168-72. doi: 10.1016/j.bcmd.2015.06.004

93. Andersen MH. The Targeting of Immunosuppressive Mechanisms in Hematological Malignancies. Leukemia (2014) 28(9):1784-92. doi: 10.1038/leu.2014.108

94. Green MR, Monti S, Rodig SJ, Juszczynski P, Currie T, O’Donnell E, et al. Integrative Analysis Reveals Selective 9p24.1 Amplification, Increased PD-1 Ligand Expression, and Further Induction via JAK2 in Nodular Sclerosing Hodgkin Lymphoma and Primary Mediastinal Large B-Cell Lymphoma. Blood (2010) 116(17):3268-77. doi: 10.1182/blood-2010-05-282780

95. Liu Z, Derkach A, Yu KJ, Yeager M, Chang YS, Chen CJ, et al. Patterns of Human Leukocyte Antigen Class I and Class II Associations and Cancer. Cancer Res (2021) 81(4):1148-52. doi: 10.1158/0008-5472.CAN-20-2292

96. Wang SS, Carrington M, Berndt SI, Slager SL, Bracci PM, Voutsinas J, et al. HLA Class I and II Diversity Contributes to the Etiologic Heterogeneity of Non-Hodgkin Lymphoma Subtypes. Cancer Res (2018) 78(14):4086-96. doi: 10.1158/0008-5472.CAN-17-2900

97. Brouwer RE, van der Heiden P, Schreuder GM, Mulder A, Datema G, Anholts JD, et al. Loss or Downregulation of HLA Class I Expression at the Allelic Level in Acute Leukemia Is Infrequent But Functionally Relevant, and can be Restored by Interferon. Hum Immunol (2002) 63(3):200-10. doi: $10.1016 /$ s0198-8859(01)00381-0 
98. Liu L, Chang YJ, Xu LP, Zhang XH, Wang Y, Liu KY, et al. T Cell Exhaustion Characterized by Compromised MHC Class I and II Restricted Cytotoxic Activity Associates With Acute B Lymphoblastic Leukemia Relapse After Allogeneic Hematopoietic Stem Cell Transplantation. Clin Immunol (2018) 190:32-40. doi: 10.1016/j.clim.2018.02.009

99. Babor F, Manser AR, Fischer JC, Scherenschlich N, Enczmann J, Chazara O, et al. KIR Ligand C2 Is Associated With Increased Susceptibility to Childhood ALL and Confers an Elevated Risk for Late Relapse. Blood (2014) 124(14):2248-51. doi: 10.1182/blood-2014-05-572065

100. Reusing SB, Manser AR, Enczmann J, Mulder A, Claas FH, Carrington M, et al. Selective Downregulation of HLA-C and HLA-E in Childhood Acute Lymphoblastic Leukaemia. Br J Haematol (2016) 174(3):477-80. doi: 10.1111/bjh.13777

101. Pende D, Marcenaro S, Falco M, Martini S, Bernardo ME, Montagna D, et al. Anti-Leukemia Activity of Alloreactive NK Cells in KIR Ligand-Mismatched Haploidentical HSCT for Pediatric Patients: Evaluation of the Functional Role of Activating KIR and Redefinition of Inhibitory KIR Specificity. Blood (2009) 113(13):3119-29. doi: 10.1182/blood-2008-06-164103

102. Holling TM, Schooten E, Langerak AW, van den Elsen PJ. Regulation of MHC Class II Expression in Human T-Cell Malignancies. Blood (2004) 103 (4):1438-44. doi: 10.1182/blood-2003-05-1491

103. Takeuchi M, Miyoshi H, Asano N, Yoshida N, Yamada K, Yanagida E, et al. Human Leukocyte Antigen Class II Expression Is a Good Prognostic Factor in Adult T-Cell Leukemia/Lymphoma. Haematologica (2019) 104(8):162632. doi: $10.3324 /$ haematol.2018.205567

104. Mannelli F SI. Immunophenotyping of Acute Leukemias - From Biology to Clinical Application. In: Flow Cytometry. Rijeka: IntechOpen (2016). p. Ch. 6. doi: $10.5772 / 62332$

105. Yang K, Xu J, Liu Q, Li J, Xi Y. Expression and Significance of CD47, PD1 and PDL1 in T-Cell Acute Lymphoblastic Lymphoma/Leukemia. Pathol Res Pract (2019) 215(2):265-71. doi: 10.1016/j.prp.2018.10.021

106. Brunner-Weinzierl MC, Rudd CE. CTLA-4 and PD-1 Control of T-Cell Motility and Migration: Implications for Tumor Immunotherapy. Front Immunol (2018) 9:2737. doi: 10.3389/fimmu.2018.02737

107. Ramzi M, Iravani Saadi M, Yaghobi R, Arandi N. Dysregulated Expression of CD28 and CTLA-4 Molecules in Patients With Acute Myeloid Leukemia and Possible Association With Development of Graft Versus Host Disease After Hematopoietic Stem Cell Transplantation. Int J Organ Transplant Med (2019) 10(2):84-90.

108. Kang SH, Hwang HJ, Yoo JW, Kim H, Choi ES, Hwang SH, et al. Expression of Immune Checkpoint Receptors on T-Cells and Their Ligands on Leukemia Blasts in Childhood Acute Leukemia. Anticancer Res (2019) 39 (10):5531-9. doi: 10.21873/anticanres.13746

109. Simone R, Tenca C, Fais F, Luciani M, De Rossi G, Pesce G, et al. A Soluble Form of CTLA-4 is Present in Paediatric Patients With Acute Lymphoblastic Leukaemia and Correlates With CD1d+ Expression. PloS One (2012) 7(9): e44654. doi: 10.1371/journal.pone.0044654

110. Austin R, Smyth MJ, Lane SW. Harnessing the Immune System in Acute Myeloid Leukaemia. Crit Rev Oncol Hematol (2016) 103:62-77. doi: 10.1016/ j.critrevonc.2016.04.020

111. Mansour A, Elkhodary T, Darwish A, Mabed M. Increased Expression of Costimulatory Molecules CD86 and sCTLA-4 in Patients With Acute Lymphoblastic Leukemia. Leuk Lymphoma (2014) 55(9):2120-4. doi: $10.3109 / 10428194.2013 .869328$

112. Pastorczak A, Domka K, Fidyt K, Poprzeczko M, Firczuk M. Mechanisms of Immune Evasion in Acute Lymphoblastic Leukemia. Cancers (Basel) (2021) 13(7):1-25. doi: 10.3390/cancers 13071536

113. Four M, Cacheux V, Tempier A, Platero D, Fabbro M, Marin G, et al. PD1 and PDL1 Expression in Primary Central Nervous System Diffuse Large BCell Lymphoma Are Frequent and Expression of PD1 Predicts Poor Survival. Hematol Oncol (2017) 35(4):487-96. doi: 10.1002/hon.2375

114. Zhou Q, Munger ME, Veenstra RG, Weigel BJ, Hirashima M, Munn DH, et al. Coexpression of Tim-3 and PD-1 Identifies a CD8+ T-Cell Exhaustion Phenotype in Mice With Disseminated Acute Myelogenous Leukemia. Blood (2011) 117(17):4501-10. doi: 10.1182/blood-2010-10-310425

115. Feucht J, Kayser S, Gorodezki D, Hamieh M, Doring M, Blaeschke F, et al. TCell Responses Against CD19+ Pediatric Acute Lymphoblastic Leukemia Mediated by Bispecific T-Cell Engager (BiTE) are Regulated Contrarily by
PD-L1 and CD80/CD86 on Leukemic Blasts. Oncotarget (2016) 7 (47):76902-19. doi: 10.18632/oncotarget.12357

116. Lee-Sherick AB, Jacobsen KM, Henry CJ, Huey MG, Parker RE, Page LS, et al. MERTK Inhibition Alters the PD-1 Axis and Promotes Anti-Leukemia Immunity. JCI Insight (2018) 3(21):1-17. doi: 10.1172/jci.insight.97941

117. Hohtari H, Bruck O, Blom S, Turkki R, Sinisalo M, Kovanen PE, et al. Immune Cell Constitution in Bone Marrow Microenvironment Predicts Outcome in Adult ALL. Leukemia (2019) 33(7):1570-82. doi: 10.1038/ s41375-018-0360-1

118. Chiarini F, Lonetti A, Evangelisti C, Buontempo F, Orsini E, Evangelisti C, et al. Advances in Understanding the Acute Lymphoblastic Leukemia Bone Marrow Microenvironment: From Biology to Therapeutic Targeting. Biochim Biophys Acta (2016) 1863(3):449-63. doi: 10.1016/j.bbamcr.2015.08.015

119. Choi DC, Tremblay D, Iancu-Rubin C, Mascarenhas J. Programmed Cell Death-1 Pathway Inhibition in Myeloid Malignancies: Implications for Myeloproliferative Neoplasms. Ann Hematol (2017) 96(6):919-27. doi: 10.1007/s00277-016-2915-4

120. Christiansson L, Soderlund S, Svensson E, Mustjoki S, Bengtsson M, Simonsson B, et al. Increased Level of Myeloid-Derived Suppressor Cells, Programmed Death Receptor Ligand 1/Programmed Death Receptor 1, and Soluble CD25 in Sokal High Risk Chronic Myeloid Leukemia. PloS One (2013) 8(1):e55818. doi: 10.1371/journal.pone.0055818

121. Ju Y, Shang X, Liu Z, Zhang J, Li Y, Shen Y, et al. The Tim-3/Galectin-9 Pathway Involves in the Homeostasis of Hepatic Tregs in a Mouse Model of Concanavalin A-Induced Hepatitis. Mol Immunol (2014) 58(1):85-91. doi: 10.1016/j.molimm.2013.11.001

122. Gagliani N, Magnani CF, Huber S, Gianolini ME, Pala M, Licona-Limon P, et al. Coexpression of CD49b and LAG-3 Identifies Human and Mouse T Regulatory Type 1 Cells. Nat Med (2013) 19(6):739-46. doi: 10.1038/ nm.3179

123. Solinas C, Migliori E, De Silva P, Willard-Gallo K. LAG3: The Biological Processes That Motivate Targeting This Immune Checkpoint Molecule in Human Cancer. Cancers (Basel) (2019) 11(8):1-16. doi: 10.3390/ cancers 11081213

124. Lee HJ, Kim SN, Jeon MS, Yi T, Song SU. ICOSL Expression in Human Bone Marrow-Derived Mesenchymal Stem Cells Promotes Induction of Regulatory T Cells. Sci Rep (2017) 7:44486. doi: 10.1038/srep44486

125. Li DY, Xiong XZ. ICOS(+) Tregs: A Functional Subset of Tregs in Immune Diseases. Front Immunol (2020) 11:2104. doi: 10.3389/fimmu.2020.02104

126. Han Y, Dong Y, Yang Q, Xu W, Jiang S, Yu Z, et al. Acute Myeloid Leukemia Cells Express ICOS Ligand to Promote the Expansion of Regulatory T Cells. Front Immunol (2018) 9:2227. doi: 10.3389/fimmu.2018.02227

127. Bayon-Calderon F, Toribio ML, Gonzalez-Garcia S. Facts and Challenges in Immunotherapy for T-Cell Acute Lymphoblastic Leukemia. Int J Mol Sci (2020) 21(20):1-35. doi: 10.3390/ijms21207685

128. Zappavigna S, Cossu AM, Grimaldi A, Bocchetti M, Ferraro GA, Nicoletti GF, et al. Anti-Inflammatory Drugs as Anticancer Agents. Int J Mol Sci (2020) 21(7):1-29. doi: 10.3390/ijms21072605

129. Soegaard SH, Rostgaard K, Skogstrand K, Wiemels JL, Schmiegelow K, Hjalgrim H. Neonatal Inflammatory Markers Are Associated With Childhood B-Cell Precursor Acute Lymphoblastic Leukemia. Cancer Res (2018) 78(18):5458-63. doi: 10.1158/0008-5472.CAN-18-0831

130. Balandran JC, Purizaca J, Enciso J, Dozal D, Sandoval A, Jimenez-Hernandez E, et al. Pro-Inflammatory-Related Loss of CXCL12 Niche Promotes Acute Lymphoblastic Leukemic Progression at the Expense of Normal Lymphopoiesis. Front Immunol (2016) 7:666. doi: 10.3389/fimmu.2016.00666

131. Fleischhack G, Cipic D, Juettner J, Hasan C, Bode U. Procalcitonin-A Sensitive Inflammation Marker of Febrile Episodes in Neutropenic Children With Cancer. Intensive Care Med (2000) 26 Suppl 2:S202-11. doi: 10.1007/BF02900739

132. Park HH, Kim M, Lee BH, Lim J, Kim Y, Lee EJ, et al. Intracellular IL-4, IL10, and IFN-Gamma Levels of Leukemic Cells and Bone Marrow T Cells in Acute Leukemia. Ann Clin Lab Sci (2006) 36(1):7-15.

133. Perez-Figueroa E, Sanchez-Cuaxospa M, Martinez-Soto KA, Sanchez-Zauco N, Medina-Sanson A, Jimenez-Hernandez E, et al. Strong Inflammatory Response and Th1-Polarization Profile in Children With Acute Lymphoblastic Leukemia Without Apparent Infection. Oncol Rep (2016) 35(5):2699-706. doi: 10.3892/or.2016.4657 
134. Castellheim A, Brekke OL, Espevik T, Harboe M, Mollnes TE. Innate Immune Responses to Danger Signals in Systemic Inflammatory Response Syndrome and Sepsis. Scand J Immunol (2009) 69(6):479-91. doi: 10.1111/ j.1365-3083.2009.02255.x

135. Naka K, Hoshii T, Muraguchi T, Tadokoro Y, Ooshio T, Kondo Y, et al. TGF-Beta-FOXO Signalling Maintains Leukaemia-Initiating Cells in Chronic Myeloid Leukaemia. Nature (2010) 463(7281):676-80. doi: $10.1038 /$ nature08734

136. Bernasconi P, Borsani O. Immune Escape After Hematopoietic Stem Cell Transplantation (HSCT): From Mechanisms to Novel Therapies. Cancers (Basel) (2019) 12(1):1-25. doi: 10.3390/cancers12010069

137. Wu S, Gessner R, von Stackelberg A, Kirchner R, Henze G, Seeger K. Cytokine/cytokine Receptor Gene Expression in Childhood Acute Lymphoblastic Leukemia: Correlation of Expression and Clinical Outcome at First Disease Recurrence. Cancer (2005) 103(5):1054-63. doi: 10.1002/ cncr.20869

138. Verma D, Zanetti C, Godavarthy PS, Kumar R, Minciacchi VR, Pfeiffer J, et al. Bone Marrow Niche-Derived Extracellular Matrix-Degrading Enzymes Influence the Progression of B-Cell Acute Lymphoblastic Leukemia. Leukemia (2020) 34(6):1540-52. doi: 10.1038/s41375-019-0674-7

139. Rouce RH, Shaim H, Sekine T, Weber G, Ballard B, Ku S, et al. The TGFBeta/SMAD Pathway Is an Important Mechanism for NK Cell Immune Evasion in Childhood B-Acute Lymphoblastic Leukemia. Leukemia (2016) 30(4):800-11. doi: 10.1038/leu.2015.327

140. Srivannaboon K, Shanafelt AB, Todisco E, Forte CP, Behm FG, Raimondi SC, et al. Interleukin-4 Variant (BAY 36-1677) Selectively Induces Apoptosis in Acute Lymphoblastic Leukemia Cells. Blood (2001) 97(3):752-8. doi: 10.1182/blood.v97.3.752

141. Allahbakhshian Farsani M, Kamel M, Mehrpouri M, Heris RS, Hamidpour M, Salari S, et al. The Expression of Interferon Gamma (IFN-Gamma) and Interleukin 6 (IL6) in Patients With Acute Lymphoblastic Leukemia (ALL). Pathol Oncol Res (2020) 26(1):461-6. doi: 10.1007/s12253-0180536-Z

142. Cloppenborg T, Stanulla M, Zimmermann M, Schrappe M, Welte K, Klein C. Immunosurveillance of Childhood ALL: Polymorphic Interferon-Gamma Alleles are Associated With Age at Diagnosis and Clinical Risk Groups. Leukemia (2005) 19(1):44-8. doi: 10.1038/sj.leu.2403553

143. Zhang XL, Komada Y, Chipeta J, Li QS, Inaba H, Azuma E, et al. Intracellular Cytokine Profile of T Cells From Children With Acute Lymphoblastic Leukemia. Cancer Immunol Immunother (2000) 49(3):165-72. doi: 10.1007/s002620050616

144. Eber SW, Morris SA, Schroter W, Gratzer WB. Interactions of Spectrin in Hereditary Elliptocytes Containing Truncated Spectrin Beta-Chains. J Clin Invest (1988) 81(2):523-30. doi: 10.1172/JCI113350

145. Zhao H, Zhou H, Cao Q, Wang C, Bai J, Lv P, et al. Effect of Allogeneic Blood Transfusion on Levels of IL-6 and sIL-R2 in Peripheral Blood of Children With Acute Lymphocytic Leukemia. Oncol Lett (2018) 16(1):849-52. doi: $10.3892 / \mathrm{ol} .2018 .8760$

146. Juarez J, Baraz R, Gaundar S, Bradstock K, Bendall L. Interaction of Interleukin-7 and Interleukin-3 With the CXCL12-Induced Proliferation of B-Cell Progenitor Acute Lymphoblastic Leukemia. Haematologica (2007) 92(4):450-9. doi: 10.3324/haematol.10621

147. Scupoli MT, Perbellini O, Krampera M, Vinante F, Cioffi F, Pizzolo G. Interleukin 7 Requirement for Survival of T-Cell Acute Lymphoblastic Leukemia and Human Thymocytes on Bone Marrow Stroma. Haematologica (2007) 92(2):264-6. doi: 10.3324/haematol.10356

148. Ma Z, Zhao X, Deng M, Huang Z, Wang J, Wu Y, et al. Bone Marrow Mesenchymal Stromal Cell-Derived Periostin Promotes B-ALL Progression by Modulating CCL2 in Leukemia Cells. Cell Rep (2019) 26(6):1533-43.e4. doi: 10.1016/j.celrep.2019.01.034

149. El-Maadawy EA, Elshal MF, Bakry RM, Moussa MM, El-Naby S, Talaat RM. Regulation of CD4(+)CD25(+)FOXP3(+) Cells in Pediatric Acute Lymphoblastic Leukemia (ALL): Implication of Cytokines and miRNAs. Mol Immunol (2020) 124:1-8. doi: 10.1016/j.molimm.2020.05.002

150. Hiroki ER, Erthal RP, Pereira APL, Pacholak LM, Fujita TC, Marinello PC, et al. Acute Lymphoblastic Leukemia and Regulatory T Cells: Biomarkers and Immunopathogenesis. Curr Immunol Rev (2016) 12:14-9. doi: 10.2174/ 1573395511666150923234547
151. Sakaguchi S, Yamaguchi T, Nomura T, Ono M. Regulatory T Cells and Immune Tolerance. Cell (2008) 133(5):775-87. doi: 10.1016/j.cell. 2008.05.009

152. Wu CP, Qing X, Wu CY, Zhu H, Zhou HY. Immunophenotype and Increased Presence of CD4(+)CD25(+) Regulatory T Cells in Patients With Acute Lymphoblastic Leukemia. Oncol Lett (2012) 3(2):421-4. doi: 10.3892/ol.2011.499

153. An F, Wang H, Liu Z, Wu F, Zhang J, Tao Q, et al. Influence of Patient Characteristics on Chimeric Antigen Receptor T Cell Therapy in B-Cell Acute Lymphoblastic Leukemia. Nat Commun (2020) 11(1):5928. doi: 10.1038/s41467-020-19774-x

154. Idris SZ, Hassan N, Lee LJ, Md Noor S, Osman R, Abdul-Jalil M, et al. Increased Regulatory $\mathrm{T}$ Cells in Acute Lymphoblastic Leukaemia Patients. Hematology (2016) 21(4):206-12. doi: 10.1080/10245332.2015.1101965

155. Jacobs JF, Nierkens S, Figdor CG, de Vries IJ, Adema GJ. Regulatory T Cells in Melanoma: The Final Hurdle Towards Effective Immunotherapy? Lancet Oncol (2012) 13(1):e32-42. doi: 10.1016/S1470-2045(11)70155-3

156. Niedzwiecki M, Budzilo O, Adamkiewicz-Drozynska E, Pawlik-Gwozdecka D, Zielinski M, Maciejka-Kemblowska L, et al. CD4(+)CD25(high)CD127 (low/-)FoxP3 (+) Regulatory T-Cell Population in Acute Leukemias: A Review of the Literature. J Immunol Res (2019) 2019:2816498. doi: 10.1155/2019/2816498

157. Beyer M, Kochanek M, Darabi K, Popov A, Jensen M, Endl E, et al. Reduced Frequencies and Suppressive Function of CD4+CD25hi Regulatory T Cells in Patients With Chronic Lymphocytic Leukemia After Therapy With Fludarabine. Blood (2005) 106(6):2018-25. doi: 10.1182/blood-2005-02-0642

158. Bhattacharya K, Chandra S, Mandal C. Critical Stoichiometric Ratio of CD4 (+) CD25(+) FoxP3(+) Regulatory T Cells and CD4(+) CD25(-) Responder $\mathrm{T}$ Cells Influence Immunosuppression in Patients With B-Cell Acute Lymphoblastic Leukaemia. Immunology (2014) 142(1):124-39. doi: 10.1111/imm.12237

159. Chen Z, Zheng Y, Yang Y, Kang J, You MJ, Tian C. Abnormal Bone Marrow Microenvironment: The "Harbor" of Acute Lymphoblastic Leukemia Cells. Blood Sci (2021) 3(2):29-34. doi: 10.1097/bs9.0000000000000071

160. Purizaca J, Contreras-Quiroz A, Dorantes-Acosta E, Vadillo E, ArriagaPizano L, Fuentes-Figueroa S, et al. Lymphoid Progenitor Cells From Childhood Acute Lymphoblastic Leukemia Are Functionally Deficient and Express High Levels of the Transcriptional Repressor Gfi-1. Clin Dev Immunol (2013) 2013:349067. doi: 10.1155/2013/349067

161. Makanga DR, Da Rin de Lorenzo F, David G, Willem C, Dubreuil L, Legrand $\mathrm{N}$, et al. Genetic and Molecular Basis of Heterogeneous NK Cell Responses Against Acute Leukemia. Cancers (Basel) (2020) 12(7):1-18. doi: 10.3390/ cancers 12071927

162. Foley B, Ta C, Barnes S, de Jong E, Nguyen M, Cheung LC, et al. Identifying the Optimal Donor for Natural Killer Cell Adoptive Therapy to Treat Paediatric B- and T-Cell Acute Lymphoblastic Leukaemia. Clin Transl Immunol (2020) 9(7):e1151. doi: 10.1002/cti2.1151

163. Zahran AM, Shibl A, Rayan A, Mohamed M, Osman AMM, Saad K, et al. Increase in Polymorphonuclear Myeloid-Derived Suppressor Cells and Regulatory T-Cells in Children With B-Cell Acute Lymphoblastic Leukemia. Sci Rep (2021) 11(1):15039. doi: 10.1038/s41598-021-94469-x

164. Parker KH, Beury DW, Ostrand-Rosenberg S. Myeloid-Derived Suppressor Cells: Critical Cells Driving Immune Suppression in the Tumor Microenvironment. Adv Cancer Res (2015) 128:95-139. doi: 10.1016/ bs.acr.2015.04.002

165. Labib Salem M, Zidan AA, Ezz El-Din El-Naggar R, Attia Saad M, ElShanshory M, Bakry U, et al. Myeloid-Derived Suppressor Cells and Regulatory T Cells Share Common Immunoregulatory Pathways-Related microRNAs That Are Dysregulated by Acute Lymphoblastic Leukemia and Chemotherapy. Hum Immunol (2021) 82(1):36-45. doi: 10.1016/ j.humimm.2020.10.009

166. Salem ML, El-Shanshory MR, Abdou SH, Attia MS, Sobhy SM, Zidan MF, et al. Chemotherapy Alters the Increased Numbers of Myeloid-Derived Suppressor and Regulatory T Cells in Children With Acute Lymphoblastic Leukemia. Immunopharmacol Immunotoxicol (2018) 40(2):158-67. doi: 10.1080/08923973.2018.1424897

167. Lee CR, Lee W, Cho SK, Park SG. Characterization of Multiple Cytokine Combinations and TGF-Beta on Differentiation and Functions of Myeloid- 
Derived Suppressor Cells. Int J Mol Sci (2018) 19(3):1-12. doi: 10.3390/ ijms19030869

168. Bingle L, Brown NJ, Lewis CE. The Role of Tumour-Associated Macrophages in Tumour Progression: Implications for New Anticancer Therapies. J Pathol (2002) 196(3):254-65. doi: 10.1002/path.1027

169. Chen SY, Yang X, Feng WL, Liao JF, Wang LN, Feng L, et al. Organ-Specific Microenvironment Modifies Diverse Functional and Phenotypic Characteristics of Leukemia-Associated Macrophages in Mouse T Cell Acute Lymphoblastic Leukemia. J Immunol (2015) 194(6):2919-29. doi: 10.4049/jimmunol.1400451

170. Li Y, You MJ, Yang Y, Hu D, Tian C. The Role of Tumor-Associated Macrophages in Leukemia. Acta Haematol (2020) 143(2):112-7. doi: 10.1159/000500315

171. Valencia J, MF-S L, Fraile-Ramos A, Sacedon R, Jimenez E, Vicente A, et al. Acute Lymphoblastic Leukaemia Cells Impair Dendritic Cell and Macrophage Differentiation: Role of BMP4. Cells (2019) 8(7):1-14. doi: $10.3390 /$ cells 8070722

172. Steidl C, Lee T, Shah SP, Farinha P, Han G, Nayar T, et al. Tumor-Associated Macrophages and Survival in Classic Hodgkin's Lymphoma. N Engl J Med (2010) 362(10):875-85. doi: 10.1056/NEJMoa0905680

173. Chen S, Yang X, Feng W, Yang F, Wang R, Chen C, et al. Characterization of Peritoneal Leukemia-Associated Macrophages in Notch1-Induced Mouse T Cell Acute Lymphoblastic Leukemia. Mol Immunol (2017) 81:35-41. doi: 10.1016/j.molimm.2016.11.014

174. Anand P, Guillaumet-Adkins A, Dimitrova V, Yun H, Drier Y, Sotudeh N, et al. Single-Cell RNA-Seq Reveals Developmental Plasticity With Coexisting Oncogenic States and Immune Evasion Programs in ETP-ALL. Blood (2021) 137(18):2463-80. doi: 10.1182/blood.2019004547

175. Nuñez-Enriquez JC, Barcenas-Lopez DA, Hidalgo-Miranda A, JimenezHernandez E, Bekker-Mendez VC, Flores-Lujano J, et al. Gene Expression Profiling of Acute Lymphoblastic Leukemia in Children With Very Early Relapse. Arch Med Res (2016) 47(8):644-55. doi: 10.1016/j.arcmed.2016.12.005

176. Dorantes-Acosta E, Pelayo R. Lineage Switching in Acute Leukemias: A Consequence of Stem Cell Plasticity? Bone Marrow Res (2012) 2012:406796. doi: $10.1155 / 2012 / 406796$

177. Goardon N, Marchi E, Atzberger A, Quek L, Schuh A, Soneji S, et al. Coexistence of LMPP-Like and GMP-Like Leukemia Stem Cells in Acute Myeloid Leukemia. Cancer Cell (2011) 19(1):138-52. doi: 10.1016/ j.ccr.2010.12.012

178. Park BG, Park CJ, Jang S, Seo EJ, Chi HS, Lee JH. Erythroleukemia Relapsing as Precursor B-Cell Lymphoblastic Leukemia. Korean J Lab Med (2011) 31 (2):81-5. doi: 10.3343/kjlm.2011.31.2.81

179. Schmidt CA, Przybylski GK. What can We Learn From Leukemia as for the Process of Lineage Commitment in Hematopoiesis? Int Rev Immunol (2001) 20(1):107-15. doi: 10.3109/08830180109056725

180. Horgan C, Kartsios C, Nikolousis E, Shankara P, Kishore B, Lovell R, et al. First Case of Near Haploid Philadelphia Negative B-Cell Acute Lymphoblastic Leukaemia Relapsing as Acute Myeloid Leukemia Following Allogeneic Hematopoietic Stem Cell Transplantation. Leuk Res Rep (2020) 14:100213. doi: 10.1016/j.lrr.2020.100213

181. Nutt SL, Heavey B, Rolink AG, Busslinger M. Commitment to the BLymphoid Lineage Depends on the Transcription Factor Pax5. Nature (1999) 401(6753):556-62. doi: 10.1038/44076

182. Hong Z, Wei Z, Xie T, Fu L, Sun J, Zhou F, et al. Targeting Chemokines for Acute Lymphoblastic Leukemia Therapy. J Hematol Oncol (2021) 14(1):48. doi: 10.1186/s13045-021-01060-y

183. Gaggero S, Witt K, Carlsten M, Mitra S. Cytokines Orchestrating the Natural Killer-Myeloid Cell Crosstalk in the Tumor Microenvironment: Implications for Natural Killer Cell-Based Cancer Immunotherapy. Front Immunol (2020) 11:621225. doi: 10.3389/fimmu.2020.621225

184. Pinho S, Frenette PS. Haematopoietic Stem Cell Activity and Interactions With the Niche. Nat Rev Mol Cell Biol (2019) 20(5):303-20. doi: 10.1038/ s41580-019-0103-9

185. Witkowski MT, Dolgalev I, Evensen NA, Ma C, Chambers T, Roberts KG, et al. Extensive Remodeling of the Immune Microenvironment in B Cell Acute Lymphoblastic Leukemia. Cancer Cell (2020) 37(6):867-82 e12. doi: 10.1016/j.ccell.2020.04.015

186. Krevvata M, Silva BC, Manavalan JS, Galan-Diez M, Kode A, Matthews BG, et al. Inhibition of Leukemia Cell Engraftment and Disease Progression in
Mice by Osteoblasts. Blood (2014) 124(18):2834-46. doi: 10.1182/blood2013-07-517219

187. Anderson D, Skut P, Hughes AM, Ferrari E, Tickner J, Xu J, et al. The Bone Marrow Microenvironment of Pre-B Acute Lymphoblastic Leukemia at SingleCell Resolution. Sci Rep (2020) 10(1):19173. doi: 10.1038/s41598-020-76157-4

188. Shafat MS, Gnaneswaran B, Bowles KM, Rushworth SA. The Bone Marrow Microenvironment - Home of the Leukemic Blasts. Blood Rev (2017) 31 (5):277-86. doi: 10.1016/j.blre.2017.03.004

189. Polak R, de Rooij B, Pieters R, den Boer ML. B-Cell Precursor Acute Lymphoblastic Leukemia Cells Use Tunneling Nanotubes to Orchestrate Their Microenvironment. Blood (2015) 126(21):2404-14. doi: 10.1182/ blood-2015-03-634238

190. Soundara Rajan T, Gugliandolo A, Bramanti P, Mazzon E. Tunneling Nanotubes-Mediated Protection of Mesenchymal Stem Cells: An Update From Preclinical Studies. Int J Mol Sci (2020) 21(10):1-10. doi: 10.3390/ ijms 21103481

191. Scharff B, Modvig S, Marquart HV, Christensen C. Integrin-Mediated Adhesion and Chemoresistance of Acute Lymphoblastic Leukemia Cells Residing in the Bone Marrow or the Central Nervous System. Front Oncol (2020) 10:775. doi: 10.3389/fonc.2020.00775

192. Berrazouane S, Doucet A, Boisvert M, Barabe F, Aoudjit F. VLA-4 Induces Chemoresistance of T Cell Acute Lymphoblastic Leukemia Cells via PYK2Mediated Drug Efflux. Cancers (Basel) (2021) 13(14):1-15. doi: 10.3390/ cancers 13143512

193. Klamer S, Voermans C. The Role of Novel and Known Extracellular Matrix and Adhesion Molecules in the Homeostatic and Regenerative Bone Marrow Microenvironment. Cell Adh Migr (2014) 8(6):563-77. doi: 10.4161/ 19336918.2014.968501

194. Xu L, Liu L, Yao D, Zeng X, Zhang Y, Lai J, et al. PD-1 and TIGIT Are Highly Co-Expressed on CD8(+) T Cells in AML Patient Bone Marrow. Front Oncol (2021) 11:686156. doi: 10.3389/fonc.2021.686156

195. Kato M, Manabe A. Treatment and Biology of Pediatric Acute Lymphoblastic Leukemia. Pediatr Int (2018) 60(1):4-12. doi: 10.1111/ped.13457

196. Malard F, Mohty M. Acute Lymphoblastic Leukaemia. Lancet (2020) 395 (10230):1146-62. doi: 10.1016/S0140-6736(19)33018-1

197. Terwilliger T, Abdul-Hay M. Acute Lymphoblastic Leukemia: A Comprehensive Review and 2017 Update. Blood Cancer J (2017) 7(6): e577. doi: 10.1038/bcj.2017.53

198. Giebel S, Labopin M, Socie G, Beelen D, Browne P, Volin L, et al. Improving Results of Allogeneic Hematopoietic Cell Transplantation for Adults With Acute Lymphoblastic Leukemia in First Complete Remission: An Analysis From the Acute Leukemia Working Party of the European Society for Blood and Marrow Transplantation. Haematologica (2017) 102(1):139-49. doi: 10.3324/haematol.2016.145631

199. Merli P, Algeri M, Del Bufalo F, Locatelli F. Hematopoietic Stem Cell Transplantation in Pediatric Acute Lymphoblastic Leukemia. Curr Hematol Malig Rep (2019) 14(2):94-105. doi: 10.1007/s11899-019-00502-2

200. Mamcarz E, Madden R, Qudeimat A, Srinivasan A, Talleur A, Sharma A, et al. Improved Survival Rate in T-Cell Depleted Haploidentical Hematopoietic Cell Transplantation Over the Last 15 Years at a Single Institution. Bone Marrow Transplant (2020) 55(5):929-38. doi: 10.1038/s41409-019-0750-7

201. Yanir AD, Martinez CA, Sasa G, Leung K, Gottschalk S, Omer B, et al. Current Allogeneic Hematopoietic Stem Cell Transplantation for Pediatric Acute Lymphocytic Leukemia: Success, Failure and Future Perspectives-A Single-Center Experience, 2008 to 2016. Biol Blood Marrow Transplant (2018) 24(7):1424-31. doi: 10.1016/j.bbmt.2018.03.001

202. Shang Y, Zhou F. Current Advances in Immunotherapy for Acute Leukemia: An Overview of Antibody, Chimeric Antigen Receptor, Immune Checkpoint, and Natural Killer. Front Oncol (2019) 9:917. doi: 10.3389/ fonc.2019.00917

203. Shah NN, Fry TJ. Mechanisms of Resistance to CAR T Cell Therapy. Nat Rev Clin Oncol (2019) 16(6):372-85. doi: 10.1038/s41571-019-0184-6

204. Slaney CY, Wang P, Darcy PK, Kershaw MH. CARs Versus BiTEs: A Comparison Between T Cell-Redirection Strategies for Cancer Treatment. Cancer Discov (2018) 8(8):924-34. doi: 10.1158/2159-8290.CD-18-0297

205. Tomuleasa C, Fuji S, Berce C, Onaciu A, Chira S, Petrushev B, et al. Chimeric Antigen Receptor T-Cells for the Treatment of B-Cell Acute Lymphoblastic Leukemia. Front Immunol (2018) 9:239. doi: 10.3389/fimmu.2018.00239 
206. Weiner LM, Surana R, Wang S. Monoclonal Antibodies: Versatile Platforms for Cancer Immunotherapy. Nat Rev Immunol (2010) 10(5):317-27. doi: $10.1038 /$ nri2744

207. Armand P, Lesokhin A, Borrello I, Timmerman J, Gutierrez M, Zhu L, et al. A Phase 1b Study of Dual PD-1 and CTLA-4 or KIR Blockade in Patients With Relapsed/Refractory Lymphoid Malignancies. Leukemia (2021) 35 (3):777-86. doi: 10.1038/s41375-020-0939-1

208. McNeer JL, Rau RE, Gupta S, Maude SL, O’Brien MM. Cutting to the Front of the Line: Immunotherapy for Childhood Acute Lymphoblastic Leukemia. Am Soc Clin Oncol Educ Book (2020) 40:1-12. doi: 10.1200/EDBK_278171

209. Duell J, Dittrich M, Bedke T, Mueller T, Eisele F, Rosenwald A, et al. Frequency of Regulatory T Cells Determines the Outcome of the T-CellEngaging Antibody Blinatumomab in Patients With B-Precursor ALL. Leukemia (2017) 31(10):2181-90. doi: 10.1038/leu.2017.41

210. Bosse KR, Majzner RG, Mackall CL, Maris JM. Immune-Based Approaches for the Treatment of Pediatric Malignancies. Annu Rev Cancer Biol (2020) 4:353-70. doi: 10.1146/annurev-cancerbio-030419-033436

211. Caliendo F, Dukhinova M, Siciliano V. Engineered Cell-Based Therapeutics: Synthetic Biology Meets Immunology. Front Bioeng Biotechnol (2019) 7:43. doi: 10.3389/fbioe.2019.00043

212. Shah NN, Maatman T, Hari P, Johnson B. Multi Targeted CAR-T Cell Therapies for B-Cell Malignancies. Front Oncol (2019) 9:146. doi: 10.3389/ fonc. 2019.00146

213. Zhang X, Li JJ, Lu PH. Advances in the Development of Chimeric Antigen Receptor-T-Cell Therapy in B-Cell Acute Lymphoblastic Leukemia. Chin Med J (Engl) (2020) 133(4):474-82. doi: 10.1097/CM9.0000000000000638

214. Biondi A, Magnani CF, Tettamanti S, Gaipa G, Biagi E. Redirecting T Cells With Chimeric Antigen Receptor (CAR) for the Treatment of Childhood Acute Lymphoblastic Leukemia. J Autoimmun (2017) 85:141-52. doi: 10.1016/j.jaut.2017.08.003

215. Pan J, Niu Q, Deng B, Liu S, Wu T, Gao Z, et al. CD22 CAR T-Cell Therapy in Refractory or Relapsed B Acute Lymphoblastic Leukemia. Leukemia (2019) 33(12):2854-66. doi: 10.1038/s41375-019-0488-7

216. Lischka A, Popow C, Simbruner G. [Can Muscle Relaxation Prevent the Development of Pneumothorax in Artificially Ventilated Newborn Infants]? Wien Klin Wochenschr (1987) 99(18):636-8.

217. Kristensen NP, Heeke C, Tvingsholm SA, Bjerregaard A-M, Draghi A, Bentzen AK, et al. Neoepitope-Specific CD8+ T Cells in Adoptive T-Cell Transfer [abstract]. In: Proceedings of the AACR Special Conference on Tumor Immunology and Immunotherapy; 2019 Nov 17-20; Boston, MA. Philadelphia (PA): AACR. Cancer Immunol Res (2020) 8(3 Suppl):Abstract nr A14.

218. Met O, Jensen KM, Chamberlain CA, Donia M, Svane IM. Principles of Adoptive T Cell Therapy in Cancer. Semin Immunopathol (2019) 41(1):4958. doi: 10.1007/s00281-018-0703-z

219. Vormehr M, Reinhard K, Blatnik R, Josef K, Beck JD, Salomon N, et al. A non-Functional Neoepitope Specific CD8(+) T-Cell Response Induced by Tumor Derived Antigen Exposure In Vivo. Oncoimmunology (2019) 8 (3):1553478. doi: 10.1080/2162402X.2018.1553478

220. Maleki Vareki S. High and Low Mutational Burden Tumors Versus Immunologically Hot and Cold Tumors and Response to Immune Checkpoint Inhibitors. J Immunother Cancer (2018) 6(1):157. doi: 10.1186/s40425-018-0479-7
221. Guedan S, Ruella M, June CH. Emerging Cellular Therapies for Cancer. Annu Rev Immunol (2019) 37:145-71. doi: 10.1146/annurev-immunol042718-041407

222. Saghafian-Hedengren S, Soderstrom I, Sverremark-Ekstrom E, Nilsson A. Insights Into Defective Serological Memory After Acute Lymphoblastic Leukaemia Treatment: The Role of the Plasma Cell Survival Niche, Memory B-Cells and Gut Microbiota in Vaccine Responses. Blood Rev (2018) 32(1):71-80. doi: 10.1016/j.blre.2017.08.009

223. Dougan SK, Dougan M. Regulation of Innate and Adaptive Antitumor Immunity by IAP Antagonists. Immunotherapy (2018) 10(9):787-96. doi: 10.2217/imt-2017-0185

224. Rohde K, Kleinesudeik L, Roesler S, Lowe O, Heidler J, Schroder K, et al. A Bak-Dependent Mitochondrial Amplification Step Contributes to Smac Mimetic/Glucocorticoid-Induced Necroptosis. Cell Death Differ (2017) 24 (1):83-97. doi: 10.1038/cdd.2016.102

225. Mezzatesta C, Bornhauser BC. Exploiting Necroptosis for Therapy of Acute Lymphoblastic Leukemia. Front Cell Dev Biol (2019) 7:40. doi: 10.3389/ fcell.2019.00040

226. Frank D, Vince JE. Pyroptosis Versus Necroptosis: Similarities, Differences, and Crosstalk. Cell Death Differ (2019) 26(1):99-114. doi: 10.1038/s41418018-0212-6

227. Li KP, Shanmuganad S, Carroll K, Katz JD, Jordan MB, Hildeman DA. Dying to Protect: Cell Death and the Control of T-Cell Homeostasis. Immunol Rev (2017) 277(1):21-43. doi: 10.1111/imr.12538

228. F G. A Phase I-II Open Label Non-Randomized Study Using TL32711 for Patients With Acute Myelogenous Leukemia, Myelodysplastic Syndrome and Acute Lymphoblastic Leukemia. Philadelphia, Pennsylvania, United States (2021).

229. Lohmann C, Muschaweckh A, Kirschnek S, Jennen L, Wagner H, Hacker G. Induction of Tumor Cell Apoptosis or Necrosis by Conditional Expression of Cell Death Proteins: Analysis of Cell Death Pathways and In Vitro Immune Stimulatory Potential. J Immunol (2009) 182(8):4538-46. doi: 10.4049/ jimmunol.0803989

Conflict of Interest: The authors declare that the research was conducted in the absence of any commercial or financial relationships that could be construed as a potential conflict of interest.

Publisher's Note: All claims expressed in this article are solely those of the authors and do not necessarily represent those of their affiliated organizations, or those of the publisher, the editors and the reviewers. Any product that may be evaluated in this article, or claim that may be made by its manufacturer, is not guaranteed or endorsed by the publisher.

Copyright (c) 2021 Jiménez-Morales, Aranda-Uribe, Pérez-Amado, RamírezBello and Hidalgo-Miranda. This is an open-access article distributed under the terms of the Creative Commons Attribution License (CC BY). The use, distribution or reproduction in other forums is permitted, provided the original author(s) and the copyright owner(s) are credited and that the original publication in this journal is cited, in accordance with accepted academic practice. No use, distribution or reproduction is permitted which does not comply with these terms. 


\section{GLOSSARY}

\begin{tabular}{|c|c|}
\hline ACT & adoptive $\mathrm{T}$ cell therapy \\
\hline ALL & acute lymphoblastic leukemia \\
\hline alloHSCT & allogeneic hematopoietic stem cell transplantation \\
\hline AML & acute myeloid leukemia \\
\hline APCs & antigen-presenting cells \\
\hline BiTEs & bispecific $\mathrm{T}$-cell engagers \\
\hline CAR & chimeric antigen receptor \\
\hline $\mathrm{CHL}$ & classical Hodgkin lymphoma \\
\hline CML & chronic myeloid leukemia \\
\hline CTLA-4 & cytotoxic T-lymphocyte-associated protein 4 \\
\hline CTLS & cytotoxic T cells \\
\hline CXCL & IFN $\gamma$-inducible chemokine (C-X-C motif) ligands \\
\hline DAMPS & damage-associated molecular patterns \\
\hline EBF1 & EBF transcription factor 1 \\
\hline ETV6 & ETS variant transcription factor 6 \\
\hline FDA & Food and Drug Administration \\
\hline FLT3 & Fms-related receptor tyrosine kinase 3 \\
\hline HLA & human leukocyte antigen \\
\hline HLA-G & human leukocyte antigen $\mathrm{G}$ \\
\hline IAP: ICOS & inducible co-stimulator \\
\hline ICOS-L & ICOS ligand \\
\hline IFN- $\gamma$ & interferon gamma \\
\hline IL & interleukin \\
\hline INF- $\alpha$ & interferon alpha \\
\hline KIR2DL1 & natural killer cell inhibition receptor \\
\hline KMT2A & lysine methyltransferase 2A \\
\hline LAG-3 & Iymphocyte-activation gene 3 \\
\hline LAMs & leukemia-associated macrophages \\
\hline mAbs & monoclonal anti-bodies \\
\hline MSCs & mesenchymal stromal cells \\
\hline MDSCs & myeloid-derived suppressor cells \\
\hline $\mathrm{MHC}$ & major histocompatibility complex \\
\hline MLL & lysine methyltransferase $2 \mathrm{~A}$ \\
\hline MPO & myeloperoxidase \\
\hline $\mathrm{NHL}$ & non-Hodgkin lymphoma \\
\hline NK & natural killer \\
\hline NKG2D & natural killer group 2 member D \\
\hline NKT & natural killer T \\
\hline OS & overall survival \\
\hline PAX5 & paired box 5 \\
\hline PD1 & programmed death 1 \\
\hline PD-L1 & programmed death 1 ligand \\
\hline pre-B & B cell precursor \\
\hline RUNX1 & RUNX family transcription factor 1 \\
\hline SAP & (SLAM)-associated protein \\
\hline scFvs & single-chain variable fragment \\
\hline SMAC & second mitochondrial activator of caspases \\
\hline TAMs & tumor-associated macrophages \\
\hline TIM-3 & T-cell immunoglobulin and mucin domain-containing protein 3 \\
\hline Tregs & regulatory $\mathrm{T}$ cells \\
\hline TILs & tumor-infiltrating lymphocytes \\
\hline TME & tumor microenvironment \\
\hline TNF & tumor necrosis factor \\
\hline TRAIL & TNF-related apoptosis-inducing ligand \\
\hline TN & tunneling nanotubes \\
\hline ULBP-1 & UL16-binding protein \\
\hline
\end{tabular}

